\section{Measurement of microtiny-droplets using a newly developed optical fibre probe microfabricated by femtosecond pulse laser}

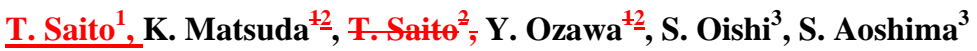

${ }^{1}$ Corresponding author, Shizuoka University, 3-5-1 Johoku, Naka-ku

Hamamatsu, Shizuoka 432-8561, Japan. E-mail: ttsaito@ipc.shizuoka.ac.jp

Shizuoka University, 3-5-1 Johoku, Naka ku Hamamatsu, Shizuoka-432 8561, Japan

${ }^{2}$ Shizuoka University, 3-5-1 Johoku, Naka-ku Hamamatsu, Shizuoka 432-8561, Japan Corresponding author, Shizuoka University, 3-5-1 Johoku, Naka-ku Hamamatsu, Shizuoka432 8561, Japan.Email: ttsaito@ipeshizuoka.ac.jp

${ }^{3}$ CRL, Hamamatsu Photonics K.K.,_5000 Hirakuchi, Hamakita-ku Hamamatsu, Shizuoka, 434-8601

\begin{abstract}
Optical fibre probing is widely applied to measurement in gas-liquid ${ }^{4}$ two-phase flows. We already developed and reported a Four-Tip Optical fibre Probe (F-TOP) for millimetre-size bubbles/droplets, and a Single-Tip Optical fibre Probe (S-TOP equipped with a wedge-shaped tip) for sub-millimetre-size bubbles/droplets. However, it is difficult to measure micrometre-size bubbles/droplets by S-TOP. The main purpose of the present study was to develop a new type of optical fibre probe micro-fabricated by a femtosecond pulse laser (fs-ProbeFs-TOP). First, we confirmed the performance of the new probe by examining millimetre- and sub-millimetre-size droplets; the results by fs-ProbeFs-TOP were compared with those obtained from the visualization of the droplets by high-speed video camera, and showed satisfactory agreement. In addition, we demonstrated the measurement of velocities and chord lengths of micrometre-size droplets (about $50 \mu \mathrm{m}$ in diameter) using the fs ProbeFs-
\end{abstract}

書式変更：間隔 段落前： $0 \mathrm{pt}$, 段落後

$0 \mathrm{pt}$

書式変更：フォント：Times, $11 \mathrm{pt}$

書式変更：Authors、行間 : 1 行

書式変更：フォント：太字（なし） 
Keywords:; Optical fi simultaneous measuren

\section{INTRODUCTION}

Gas-1Liquid two-phase Recently, demands for a variety of research power plants, and so bubbles/droplets at hi industrial use. Various very difficult to-fin industrial needs_has measurement of gasmethod has been col equivalent diameter, useful (e.g. Mudde \& positions on measure statistical factors $(\mathrm{C}$ chord lengths and ve due to the probes' $i$ 1992, 1998), and $\mathrm{H}$ velocities, chord ler probe.

Recently, particular increased in resear

Listed in the

forerence list. $n$ with those by S-TOP to clarify the limits and robe.

robe, femtosecond pulse laser, droplet, chord length, velocity,

\section{Revised. for Q2 and Q9}

ws are frequently encountered in a wide range measurement of tiny bubbles/droplets have inere s-of: e.g., sprays, automotive engines, fine che A highly_-accuracyte measurement method for tumber-density has been yearned indesired for $b$ thods for the-such measurement have been propo = a real-time and high-accuracy measurement

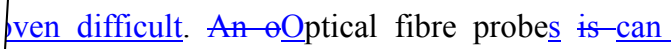
id two-phase flows (e.g. Abuaf et al 1978). Much cted. For millimetre-size bubbles/droplets (i.e., 1 eafter mm-size bubble/droplet), a multi-tip optical aito 2001; Saito et al 2001, 2004). The ifnfluences thord lengths were-has been studied in consideration k et al., 1988, 1995). However, simultaneous mea cities has been thought to need-require at least two on measurement principle. On the other hand, Catellier $e$ $\mathrm{g}$ et al (2004) have been studying the simultaneous ths and void fractions of bubbles/droplets via by a n lemands for measuring the properties of micro dropl in-multi-phase flow researchs. For the measurements dustrial fields. merged in the $y$, and atomic acterization of aboratory and however, it is od to satisfy ppplied to the earch into this $\mathrm{n}$ to $4 \mathrm{~mm}$ in probe is very the piercinged with regard to ment of their al fibre probes (1990, 1991, easurement of ofibre optical bubbles have tiny droplets/

\section{書式変更：両端揃え}

\section{書式変更}

\begin{tabular}{l} 
書式変更 \\
コメント [KN1]: ? “the probes”? \\
書式変更: フォント: Times New Roman \\
\hline 書式変更: フォント: 斜体 \\
\hline 書式変更: フォントの色 : 赤 \\
\hline 書式変更 \\
\hline \\
\hline 書式変更 \\
書式変更 \\
書式変更 \\
書式変更
\end{tabular}


bubbles via-by optical fibre probe, a multi-tip probe is not applicable; because the multi-tip optical fibre probe is too large to surely-pierce such spheresthem. In order to solve this problem, the authors developed a Single-Tip Optical-fibre Probe (S-TOP) which realizes the simultaneous measurement of chord lengths and velocities of tiny bubbles/droplets at low velocities (Saito 1999, 2002). However, it this probe is difficult tocannot measure micro droplets/bubbles at high velocities by the S-TOP owing tobecause of its measurement principle. To break throughovercome this problem, we have developed a new type of optical fibre probe micro-fabricated by femtosecond pulse laser (fs-ProbeFs-TOP), which realizes simultaneous measurement of chord lengths and velocities of tiny droplets/bubbles at high velocities.

The S-TOP and fs ProbeFs-TOP have the distinguished properties compared with the other former probes. Each optical probe hashave different kinds of characteristics; therefore, they should be used underselected with careful consideration of their application ranges-reflecting their characteristics. In the present paper, those characteristics and the comparisons of them are described and compared. B based on the eomparisons betweencorrelation of the measurement results of each of the S-TOP/fs-Probe and with those of visualization, we consider their characteristics and compare their performance as follows.

In addition, we propose various methods for interpreting the results. In a single probe method, the probe should pierce the centre region of a droplet/bubble in order to accurately measure its minor axis. First, we propose a $\mathrm{Our}$ newly developed method using a pre-signal to-can detect whether the S-TOP/fs ProbeFs-TOP has pierceds the centre region of a droplet/bubble. Second, wWe also discuss the forced deformation when the probe touches the droplet interface. Focusing on and its relation to droplet's size and velocity, we discuss this deformation. Third, wWe carefully discuss the influences of the droplet another deformation taking place of the droplet during the S-TOP/fs-Probe measurement (i.e. ; namely, that while the probe is piercing the dropleit, on the measurement resultsł. Based on these theoretical discussions, we describe interpret the actual results of millimetre-size and sub-millimetre-size (300 $600 \mu \mathrm{m}$, sub-mm-size) droplet droplet-measurements TOP. We confirm the performance and properties of the S-TOP/fs-Probe by examining millimetre droplets, sub-millimetre-size droplet (sub-mm-size droplet). In addition, we 


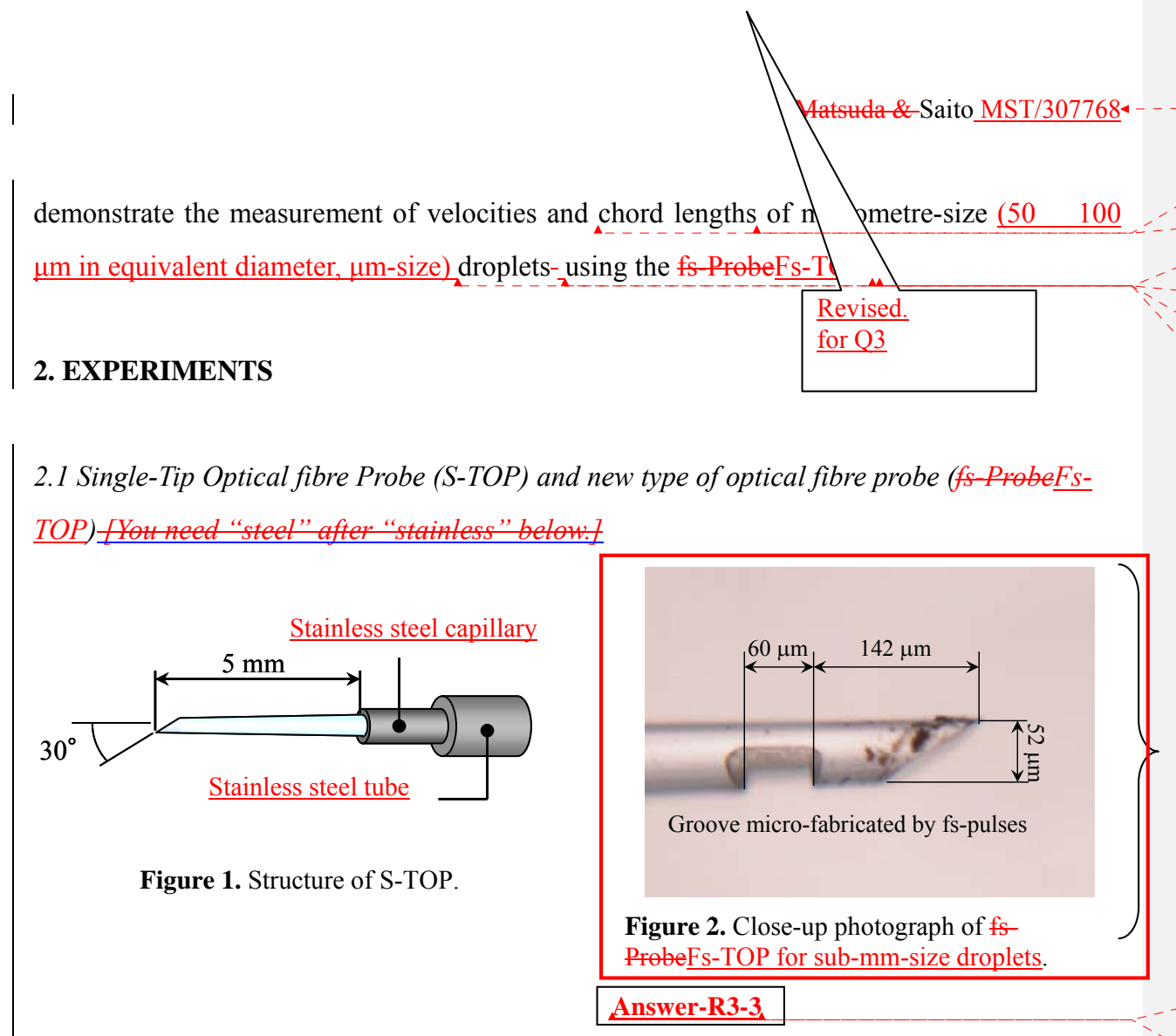

書式変更：単語の途中で改行する

\begin{tabular}{l} 
書式変更 \\
\hline 書式変更：フォント：Times New Roman \\
\hline 書式変更：フォント：Times New Roman \\
\hline 書式変更：フォント：Times New Roman \\
書式変更：フォント：Times New Roman \\
書式変更：フォント：Times New Roman \\
\hline
\end{tabular}

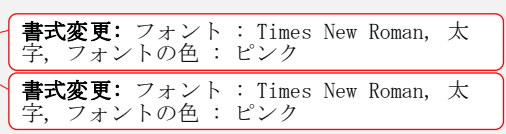

2.1.1 S-TOP. Figure 1 shows the structure of the S-TOP used in the present study. The S-TOP* 書式変更：両端揃え was made of a synthetic silica optical fibre (external diameter, $230 \mu \mathrm{m}$; core diameter, in external diameter, $190 \mu \mathrm{m}$-in core diameter; jacket thickness, $15 \mu \mathrm{m}$; refractive index in jacket thickness, 1.46 - in refractive index). The silica optical fibre was fine-drawn using a micropipette puller (P-2000, Sutter Instrument Company). After that, the tip was ground in-at

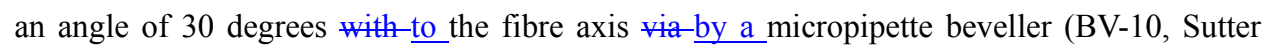
Instrument Company); the most distinguishable feature of the S-TOP is that its tip is ground 
in-at an angle of 30 degrees with-to the fibre axis. The tip diameter is $20 \mu \mathrm{m}$. This fibre was inserted and fixed in a stainless capillary. Accordingly, chord lengths and velocities of bubbles/droplets are measured using only a single--tip optical fibre probe. Furthermore, STOP is coated with a water repellent material by vacuum evaporation of a water-repellent material-in order to control the surface wettability.

2.1.2 fs-Probe Fs-TOP. Figure 2 shows the structure of the fs-ProbeFs-TOP used in the present study. The fs ProbeFs-TOP was made of a synthetic silica optical fibre (external diameter, $230 \mu \mathrm{m}_{\text {; }}$ core diameter in external diameter, $190 \mu \mathrm{m}_{2}$ jacket thickness, in core diameter, $15 \mu \mathrm{m}$; refractive index, in jacket thickness, 1.46 in refractive index). The silica optical fibre was also fine-drawn using the micropipette puller. After that, the clad near the tip was processed by femtosecond pulses. A close-up picture is shown in Figfigure- 2. Since a clad is stripped from a core at the groove, the core touches the air directly. The phase detection is done in two stages (i.e. at tip of the probe and at the groove). This fibre was inserted and fixed in a stainless capillary. TFurthermore, the fs-ProbeFs-TOP is also coated with water repellent material by vacuum evaporation-of a water repellent material.

\subsection{Rational targets for S-TOP and fs Probe FS-TOP measurements.}

The S-TOP and fs-ProbeFs-TOP have the distinguished-distinguishing properties compared ${ }^{4}$ with the other-conventional probes. Furthermore, our probes have different characteristics owing to the-differences in their ef-measurement principles and manufacturing processes. The S-TOP can be made very easily; the tip of the S-TOP is only micro-ground into a wedge shape. Hence, the wedge-shaped tip is gradually covered with the ether-opposite phase (liquid phase in the cases of the droplet measurement;- gas phase in the cases of the bubble measurement). By contrast, mAicro-fabrication of the fs-ProbeFs-TOP needs-requires a highpower femtosecond-pulse laser, nano-order 6-axes automatic optical stages, confocal optics, and so on. The fabricationIt is very difficult to make-fabricate the fs ProbeFs-TOP with the desired performance.

It is important to use intelligently both-select between these two probes due-according to the measurement objective, based on a thorough understanding of their properties. 
Figure 3 shows the - schematic diagram of the measurement processes by using the S-TOP and fs-ProbeFs-TOP. The S-TOP measures the velocities of bubbles/droplets by a very small tip. Hence, the S-TOP needs the - fast A/D converter and fast amplifier for the measurements of tiny bubbles/droplets moving at high velocity. This is a disadvantage of S-TOP measurement. Therefore, the measurement object of the S-TOP is the sub-mm-size droplet moving at less than several $\mathrm{m} / \mathrm{s}$.

On the other hand, the measurement object of the fs-ProbeFs-TOP is the $\mu$ m-size -microdroplets and sub-mm-size droplets moving at ever $10 \mathrm{~m} / \mathrm{s}$ or more. The fs-probeFs-TOP uses the signal from the probe tip and that from the groove. Hence, the time interval of the event time becomes larger than that of the S-TOP.

The S-TOP and fs ProbeFs-TOP have the-different application ranges, respectively. In this paper, we confirm the performance of the fs-ProbeFs-TOP and S-TOP by examining millimetre- and sub-mm-size droplets for the first time. When the droplet velocity is around $10 \mathrm{~m} / \mathrm{s}$, the fs-ProbeFs-TOP can highly accurately measure the droplet property with higher accuracy compared withthan the S-TOP.

\subsection{Optics and data acquisition.}

The optics system is shown in Fig.figure 4. The beam from a laser diode (a) (wavelength $635 \mathrm{~nm}$ ) is split by a beamsplitter (b), and focused on the fibre edge (d) by an objective lens (c). A p Part of the laser beam propagated through the optical fibre is reflected at the other tip (sensing side) of the optical fibre probe, changed its own polarization plane at the reflection and propagated back again through the same fibre; then it is input into a photo multiplier (f) through a polarizer (e) cutting the laser beam (i.e. the beam from the laser diode) with a different polarization plane from that of the reflected beam.Part of the laser beam propagated through the optical fibre is reflected at the other tip (sensing side) of the optical fibre probe, and propagated back again through the same fibre; then it was is input into a photo multiplier (f) through a polarizer (e) cutting a direct laser beam from the laser diode.

The optical signal was converted into an electrical signal viaby the photo multiplier (f). The electrical signal was stored in a digital oscilloscope (g) (sampling rate $200 \mathrm{MHz}$ ). 


\subsection{Experimental setups.}

Figure 5 shows a schematic diagram of the experimental setup used in demonstration of millimetre-size droplet (droplet diameter: $1 \mathrm{~mm} \leq L_{D} \leq 5 \mathrm{~mm}$;) measurement by Fs-TOP and

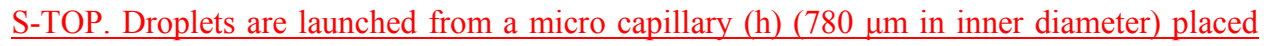
over the probe (a). The equivalent diameter of the droplets is $2 \mathrm{~mm}$, and their velocities varied between $0.25 \mathrm{~m} / \mathrm{s}$ and $2.5 \mathrm{~m} / \mathrm{s}$. We visualized the process of the droplets being pierced by the

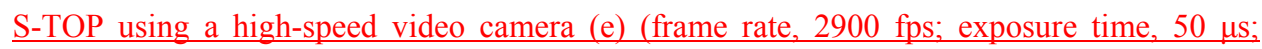
resolution, $800 \times 512$ pixel $^{2}$; and spatial resolution, $21.97 \mu \mathrm{m} /$ pixel) and a halogen light (g).

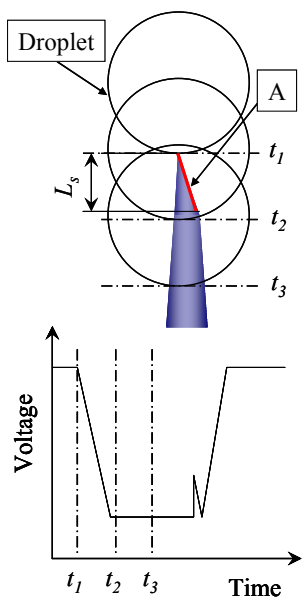

(a) S-TOP

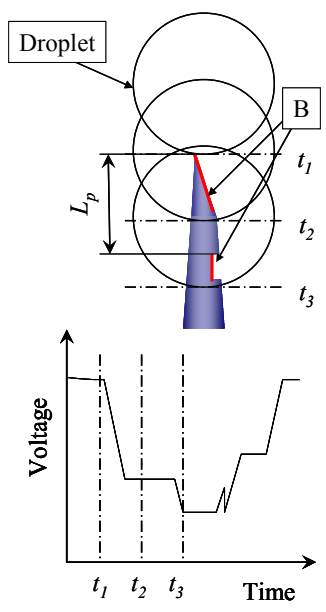

(b) fs-Probe

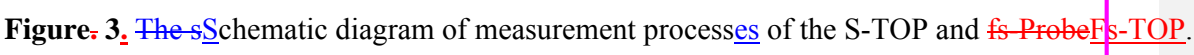

(f)

(e)

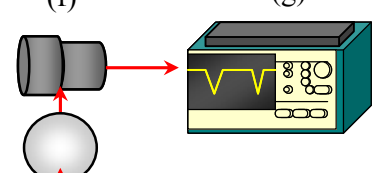

(a)

(b) (c)

(d)
Figure 4. Optics.

(a) Laser diode, (b) Beamsplitter, (c) Objective lens, (d) Optical fibre probe, (e) Polarizer,

Figure 4. Optics.

書式変更：中央揃え

書式変更：タブ位置： 4.23 字(なし) 


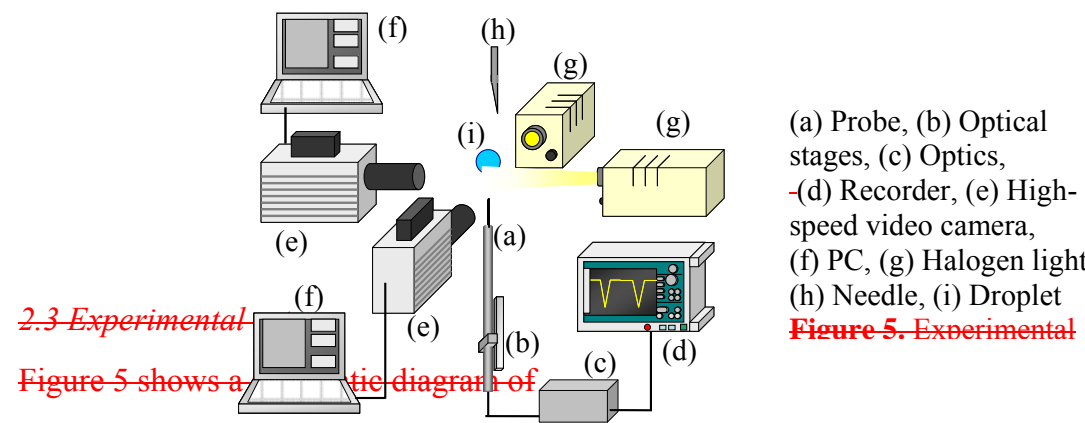

the experimental styperd (c) Optical stages, (c) Optics, (d) Recorder, (e) High-speed demonstration of millimetre-size droplets

(droplet diameter: $1 \mathrm{~mm} \leq L_{D} \leq 5 \mathrm{~mm}$;)

measurement via by fs Probe and S TOP.

Droplets are launched from a micro

eapillary (h) (780 $\mathrm{mm}$ in inner diameter)

placed over the probe (a). The equivalent

diameter of the droplets is $2 \mathrm{~mm}$, and their

velocities were varied between $0.25 \mathrm{~m} / \mathrm{s}$

and $2.5 \mathrm{~m} / \mathrm{s}$. We visualized the process of

the droplets being pierced with by the $S$ -

TOP using a high-speed video camera (e)

(frame rate $2900 \mathrm{fps}$, ; exposure time 50

$\mu \mathrm{s}$, ; resolution $2800 \times 512$ pixel $_{2}^{2}$, and 
spatial resolution $21.97 \mu \mathrm{m} /$ pixel) and a

halogen light $(\mathrm{g})$.

Figure 6 shows a schematic diagram of the experimental setup used in experiments of submm-size droplets (droplet diameter: $150 \mu \mathrm{m} \leq L_{D} \leq 500 \mu \mathrm{m}$; droplet velocity: $5 \mathrm{~m} / \mathrm{s} \leq U_{D} \leq 25$ $\mathrm{m} / \mathrm{s}$ ) measurement viaby fs-ProbeFs-TOP and S-TOP. Ion-exchange water in the a water tank (b) is was pressurized by air (a) (gauge pressure $25 \mathrm{kPa} \leq P \leq 300 \mathrm{kPa}$ ), and the pressurized water was ejected from the nozzle (nozzle diameter $D=30,60,100,150,200 \mu \mathrm{m})(\mathrm{e})$. The dDiameters of the droplets is-varied between $150 \mu \mathrm{m}$ and $500 \mu \mathrm{m}$, and their velocity was varied between $5 \mathrm{~m} / \mathrm{s}$ and $25 \mathrm{~m} / \mathrm{s}$. The probe was mounted on a three-degree-of-freedom precision micro stage (h) driven by micro stepping motors. The probe position was adjusted precisely using the micro stage, as the probe was able to strike the $\mu \mathrm{m}$-size-micre droplets. The process of the piercing of droplets with the probe was also visualized using two highspeed video cameras $\left(\mathrm{j}\right.$ ) (frame rate 250000, 500000, $1000000 \mathrm{fps} ;$ exposure time ${ }_{2} 0.5 \mu \mathrm{s}-;$ resolution, $260 \times 312$ pixels $^{2}$; ; and spatial resolution ${ }_{2} 6.67 \mu \mathrm{m} /$ pixel) $(\mathrm{k})$, and a strobe light (l) and a halogen light $(\mathrm{m})$.

Figure 7 shows the schematic diagram of the experimental setup which-used in the experiments of $\mu \mathrm{m}$-size-micre droplets measurement via by fs ProbeFs-TOP. Micrometer-size droplets (droplet diameter: $L_{D} \approx 30 \mu \mathrm{m}$, droplet velocity; $1.5 \mathrm{~m} / \mathrm{s} \leq U_{D} \leq 2.5 \mathrm{~m} / \mathrm{s}$ ) is-were ejected from the-a piezoelectric ink jet nozzle (h). We visualized the contact process between the droplets and the fs-ProbeFs-TOP by-using a Hhigh-speed video camera (e) and a s $\underline{S}$ trobe $\operatorname{light}(\mathrm{g})$.

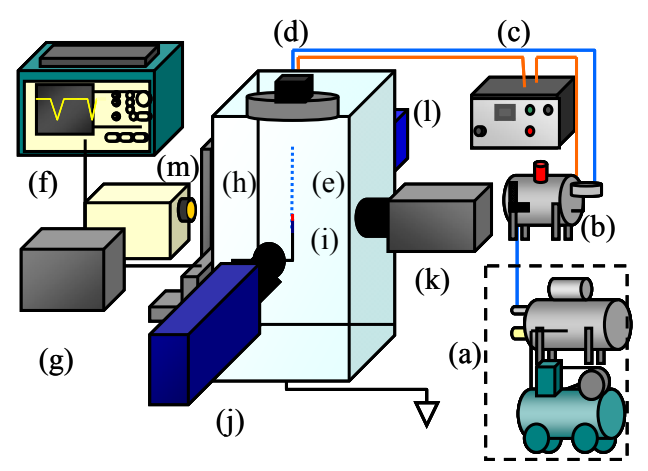

(a) Pressurization source, (b) Water tank, (c) Pressure controller, (d) Electromagnetic valve, (e) Piezo nozzle, (f) Digital oscilloscope, (g) Optical system, (h) 3-axis unit, (i) S-TOP, (j) High-speed video camera 1, (k) High-speed video camera 2, (l) Strobe light, (m) Halogen light source.

Figure 6. Experimental setup for measurement of sub-millimetre-size droplets. 


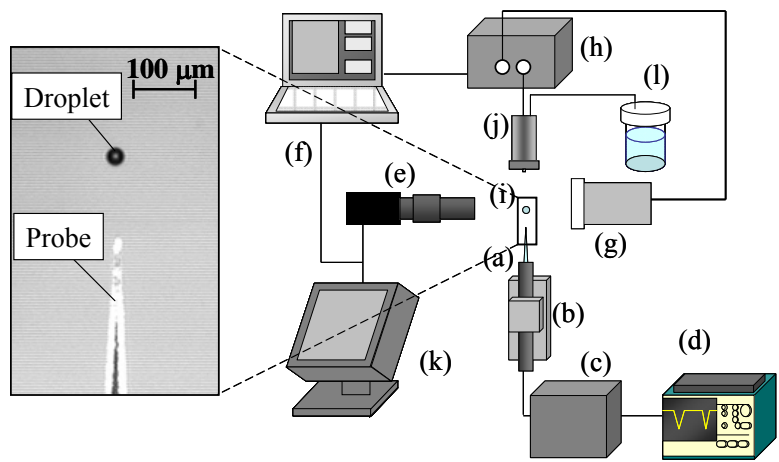

(a) Probe, (b) Optical stages, (c) Optical system, (d) Digital oscilloscope,

(e) High-speed video camera, (f) PC, (g) Strobe light, (h) Piezoelectric ink jet nozzle,

(i) Droplet,

(i) Controller, (k) Monitor, (1) Water tank

Figure 7. Experimental setup for measurement of $\underline{\mu m i c r o m e t r e-s i z e ~ d r o p l e t s . ~}$ (a) Probe, (b) Optical stages, (c) Optical system, (d) Digital oscilloscope,

(e) High-speed video camera, (f) PC, (g) Strobe light, (h) Piezoelectric ink jet nozzle, (i) Broplet,

(j) Controller, (k) Monitor, (l) Water tank

\section{SIGNAL PROCESSING}

3.1 Signal processing for S-TOP. 
3.1.1 Characteristics of S-TOP signals. A typical signal in droplet measurements via-by the STOP is plotted in figureFig. 8 . The wedge-shaped tip of the S-TOP is gradually covered with the other phase;-in consequently, ee the intensity of the light reflected at the tip is gradually changed (marked in figureFig. 8); the interface velocity is proportional to the derivative of the optical signal (derivative of the leading edge of optical signal) with respect to time (Saito $2007 \underline{\mathrm{a}, \mathrm{b}})$. Therefore, m $\underline{\mathrm{m}}$ easuring the surface tension and viscosity of measurement objects preliminarily, athe gas-liquid interface velocity is easily calculated by using this relation (e.g. Saito et al. 2000, Saito 2007 ). Accordingly, chord lengths and velocities of bubbles/droplets are-were measured using only a single--tip optical fibre probe. The gradient of a-the leading edge $g_{r d}$ is calculated by equation (1),

$$
g_{r d}=\frac{d V}{d t} \times \frac{1}{\left(V_{\text {Gas }}-V_{\text {Liquid }}\right)}
$$

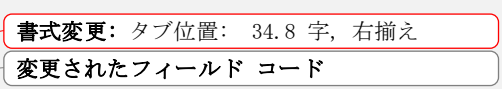

where $\mathrm{d} V / \mathrm{d} t$ is obtained from a burst signal, and the gas-phase output level $V_{\text {Gas }}$ and liquidphase level $V_{\text {Liquid }}$ are calculated as described in section 3.1.2. In a similar way, the gradient of the rising edge is calculated by the equation (1).

PThe droplet velocity $U_{D}$ (in a strict sense, the average interface velocity of a droplet) is calculated from equation (2)

$$
U_{D}=\frac{1}{\alpha} \times g_{r d}
$$

where $\alpha$ is the proportionality coefficient between the interface velocity and $g_{r d}$. The coefficient " $\alpha$ " depends on only 3 factors as follows:- the angle of the S-TOP tip, tThe wettability between the probe and the liquid phase, and tThe surface tension of the liquid phase. The angle of the S-TOP tip is decided based on the results of ray trace calculation considering the difference $\theta$ fin refraction indexes between the core of the optical fibre and the liquid phase. After that, the value of the coefficient " $\alpha$ " is decided by only the properties 
of the liquid phase (the wettability and surface tension). In this paper, these properties do not change, because we measure only water droplets.

Figure 89 shows the relationship between $g_{r d}$ obtained by S-TOP measurements and $U_{D}$ by visualization. As shown in this figure, the value of the coefficient " $\alpha$ " of the calculated value $5.60 \times 10^{-6}$ is adequate.

The chord length $L_{D}$ is calculated from equation (3),

$$
L_{D}=U_{D} \times\left(t_{e}-t_{s}\right)
$$

where $t_{s}$ and $t_{e}$ are the starting and finishing end times of contact between the S-TOP and the droplet. The event time $t_{s}$ is defined as an intersection point of the straight line (i.e. the gradient is $g_{r d}$ ) and the gas--phase level at the leading edge. The event time $t_{e}$ is defined as an the intersection point of the straight line (i.e., the gradient is $g_{e}$ ) and the liquid--phase level at the rising edge.

3.1.2 Evaluation of droplet deformation and Pre-signal. Figure 10 shows schematic drawings of the S-TOP/fs ProbeFs-TOP measurement. When the probe pierces the centre region of a droplet/bubble, the chord length obtained by probe is very similar to the droplet's/bubble's minor axis. In the measurements of droplets/bubbles, If $\underline{\text { if }} L_{M l}$ is limited within an area of $L_{M l} /$ $L_{B l}<0.3$, i.e. within the centre region, the difference between the measured chord length $L_{M}$ and the length of the minor axis of a droplet/bubble $L_{D s}$ is small $\left(0.95<L_{M s} / L_{B S}<1.00\right)$. When the probe pierces droplets/bubbles in the centre region, highly accurate measurement is achieved. In addition, the small difference between the miner-axis and measured chord lengths is a kind of random difference; therefore, it is very difficult to remove it them from the measurement results.

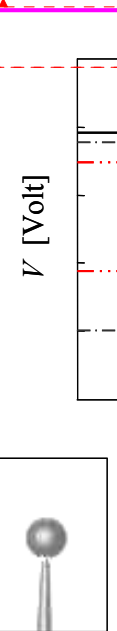

(1)
(1) (2) (3) 4

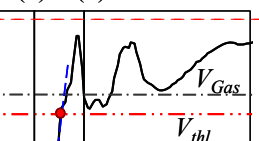

(

Pre-signal

Pre-signal

$V_{\text {th }}$

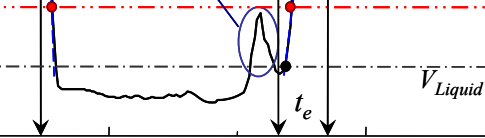

$t$

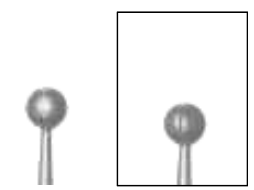

(2)
コメント [KN6]: WHAT small difference? You use the definitive article "the", which implies the reader knows which difference. But it is not clear. Define it by saying "the small difference in OR even better, "the small difference in between_and __"

書式変更：フォントの色：自動

書式変更：フォントの色：自動

書式変更：フォントの色：自動 
Figure 8. A typical signal in for droplet measurements

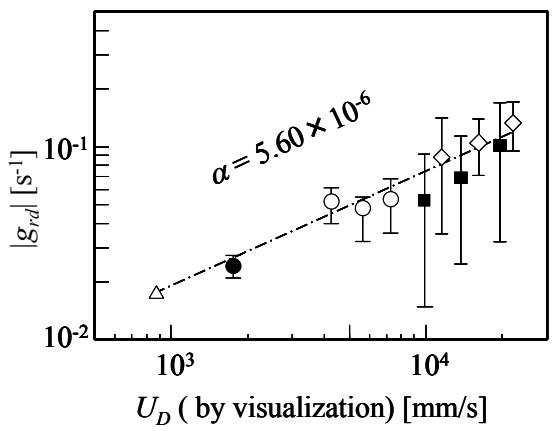

Figure 9. The relationship between $g_{r d}$ and $U_{D}$ (visualization) rearranged by using $\alpha$ of 


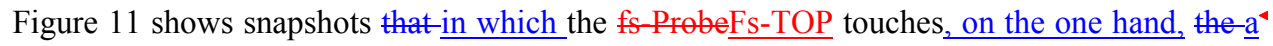
flat interface and on the other, a sub-mm-size droplet. In the cases of touching the flat interface at low velocity (a the velocity of the probe is $100 \mathrm{~mm} / \mathrm{s}$ ), a large deformation is observed en at the gas-liquid interface as shown in figureFig. 11 (a). On the other hand, when the fs-ProbeFs-TOP touches a sub-mm-size droplet at a high velocity $(10 \mathrm{~m} / \mathrm{s})$, the deformation of the droplet is very small as shown in figureFig. 11 (b). Hence, the deformation of the droplet does not become a serious problem when we measure-measuring tiny droplets moving at a high velocity. Unfortunately, this deformation is-was not measured quantitatively. The deformation of the droplet while pierced by the probe is very small during measurement (between $t_{s}$ and $t_{e}$ ), as shown in the snapshots of figureFig. 8. In the case of sub-mm-size droplet measurements, the deformation is smaller than $3.2 \%$ of droplets' minor axes (this difference is a kind of bias), and in the case of $\mu \mathrm{m}$-size-micro-size droplet measurement it is smaller than $3.1 \%$ of the droplets' minor axes (this difference is a kind of bias); i.e., the measurement is completed before large deformation. In fact, as the probe pierces the droplet in this region, highly accurate measurement is achieved. However, we need to know how to detect the pierced-position by of piercing using the single--tip optical fibre probe, to ensure that the probe has pierced the centre of the droplet.
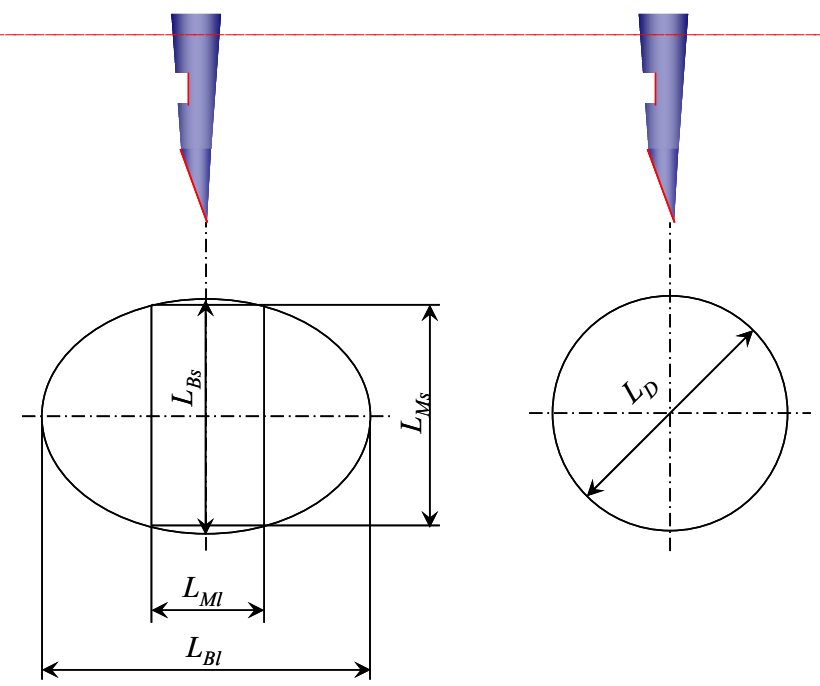

コメント [KN7]: Is this what you mean?

Figure 10. Schematic drawings of relationship between pierce region and measurement chord length. 

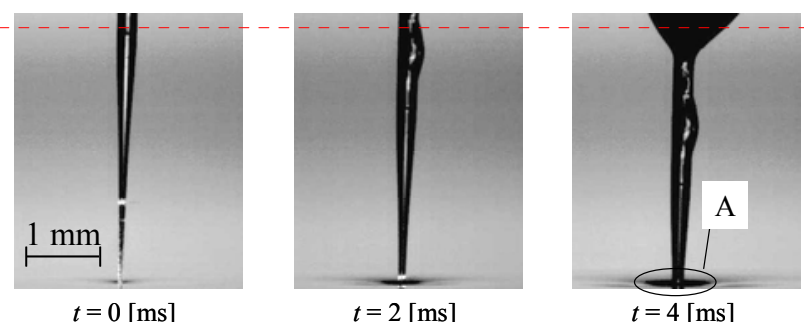

書式変更：フォントの色：自動

(a) Snapshots: The fs-Probe touching the-a flat interface ata low velocity $(100 \mathrm{~mm} / \mathrm{s})$; the fs-Probe touches the interface just at $t=0$ [ms].

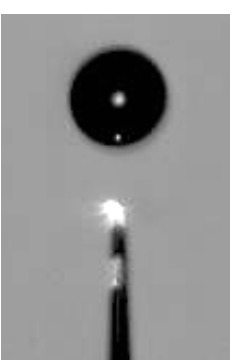

$t=0[\mu \mathrm{s}]$

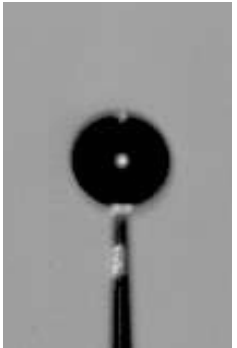

$t=2[\mu \mathrm{s}]$

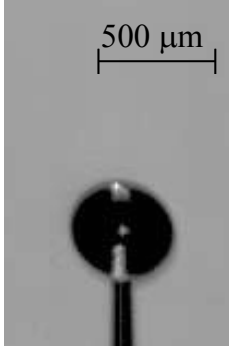

$t=4[\mu \mathrm{s}]$

(b) Snapshots: The fs-Probe touching a sub-mm-size droplet moving at a high velocity $(10 \mathrm{~m} / \mathrm{s})$;

Figure 11. Snapshots of touching process under different conditions. 
We found out that a pre-signal appears only when the wedge-shape tip of the botheither probe (equipped with wedge-shape tip)-pierces the centre region of a droplet/bubble. In the case of bubble measurement, most beams are emitted from the probe tip before they pierce athe bubble, because the probe tip is eovered withsurrounded by -liquid phase-before the detectionencountering-of the bubble. Hence, the emitted beams are reflected on the bubble frontal surface, and some of them re-enter into-the probe; this-these incident beams are-serve as a pre-signal. On the other hand, in the droplet measurement, few beams are emitted from the probe tip; because the probe tip is covered withsurrounded by gas phase-before the detection ofencountering the droplet. Therefore, no pre-signal does notappears before the detection of the droplet. However, the a pre-signal similar to the pre-signal of the bubble measurement appears just before the probe pierces the rear interface of the droplet only when the probe pierces the centre region.

In the measurement by-using a single tip probe, this measurement method realizes the-highaccuracy measurement of the minor axes of the bubbles and droplets. 
3.1.3 Algorithsm for S-TOP. Figure 12 shows the algorithsm for the processing of S-TOP signals. The signal processing is composed of four processes as described herein-below;: 1 ) the sSmoothing process, 2) the dĐetermination of thresholds, 3) the Đdetection of event time and gradient of a the burst signal, and 4) the cCalculation of chord length and velocity.

\section{1) Smoothing process}

The raw data of output signals are smoothed viaby a 25-point moving average method to reduce the influence of high-frequency noise.

\section{2) Determination of thresholds}

We use the thresholds to accurately detect the event time. First, the maximum output voltage $V_{\max }$ and the minimum output voltage $V_{\min }$ are detected. Second, $V_{\text {Gas }}$ and $V_{\text {Liquid }}$ are calculated. In this study, $V_{\text {Gas }}$ is the average value of the voltage over $90 \%$, and $V_{\text {Liquid }}$ is the averaged value of the voltage under $10 \%$. Finally, the high threshold level $V_{t h h}$ and the low threshold level $V_{t h l}$ are decided. In this study, the high threshold level $V_{t h h}$ was $90 \%$ of all-the entire signal amplitude, and the low threshold level $V_{t h l}$ was $30 \%$ of allthe entire signal amplitude. These threshold values are decided by the results of comparison between the visualization and the probe signal. As a result, the difference ef-in detection of event time between the results of visualization and signal processing is less than $5 \%$ in all measurement cases. We consider this difference is-as a kind of a bias difference (not random difference) in the calculation of event time; therefore, this bias is-could be removed from the S-TOP measurement results.

3) Detection of event time and gradient of a burst signal

In this process, we detect the $t_{s}$ at and $t_{e}$, and calculate the gradient of the signal. First, the gradient of the falling edge and rising edge is calculated by equation (1), as shown in section 3.1.1. Next ${ }_{2}$ we detect the duration time between the probe and athe droplet. The event time $t_{s}$ is defined as an-the intersection point of the straight line (i.e. the gradient is $g_{r d}$ ) and the gasphase level at the falling edge. The event time $t_{e}$ is defined as an the intersection point of the straight line (i.e. the gradient is $g_{e}$ ) and the liquid--phase level at the rising edge. As a result, 
we can calculate the event time. The bias (i.e. the difference is less than $5 \%$ of the results by visualization) is considered in the calculation.

4) Calculation of chord length and velocity

Finally, we calculate the droplet velocity and its chord length. In the calculation, we judge the piercinged position. First, we calculate the droplet velocity by equation (2) as shown in section 3.1.1. The chord length $L_{D}$ is calculated from equation (3) (shown in section 3.1.1). Next, we estimate the time range of generation of the pre-signal from droplet velocity and its diameter. We search for the pre-signal in this range-by using a threshold. As part of this process, we can judge whether the probe pierces in-the centre part of the droplet. Since-When the probe pierces the centre part of a the droplet, we can measure the minor axes of the droplets. The pre-signal is described at in detail in section 3.1.2.

3.1.4 The algorithsm for fs ProbeFs-TOP. As shown in figureFig. 13, the signal processing is composed of five processes as described below: 1) the sfmoothing process, 2) the hHistogram process, 3) the dDetermination of thresholds, 4) the dPetection of event time and gradient of signal, and 5) the cEalculation of chord length and velocity.

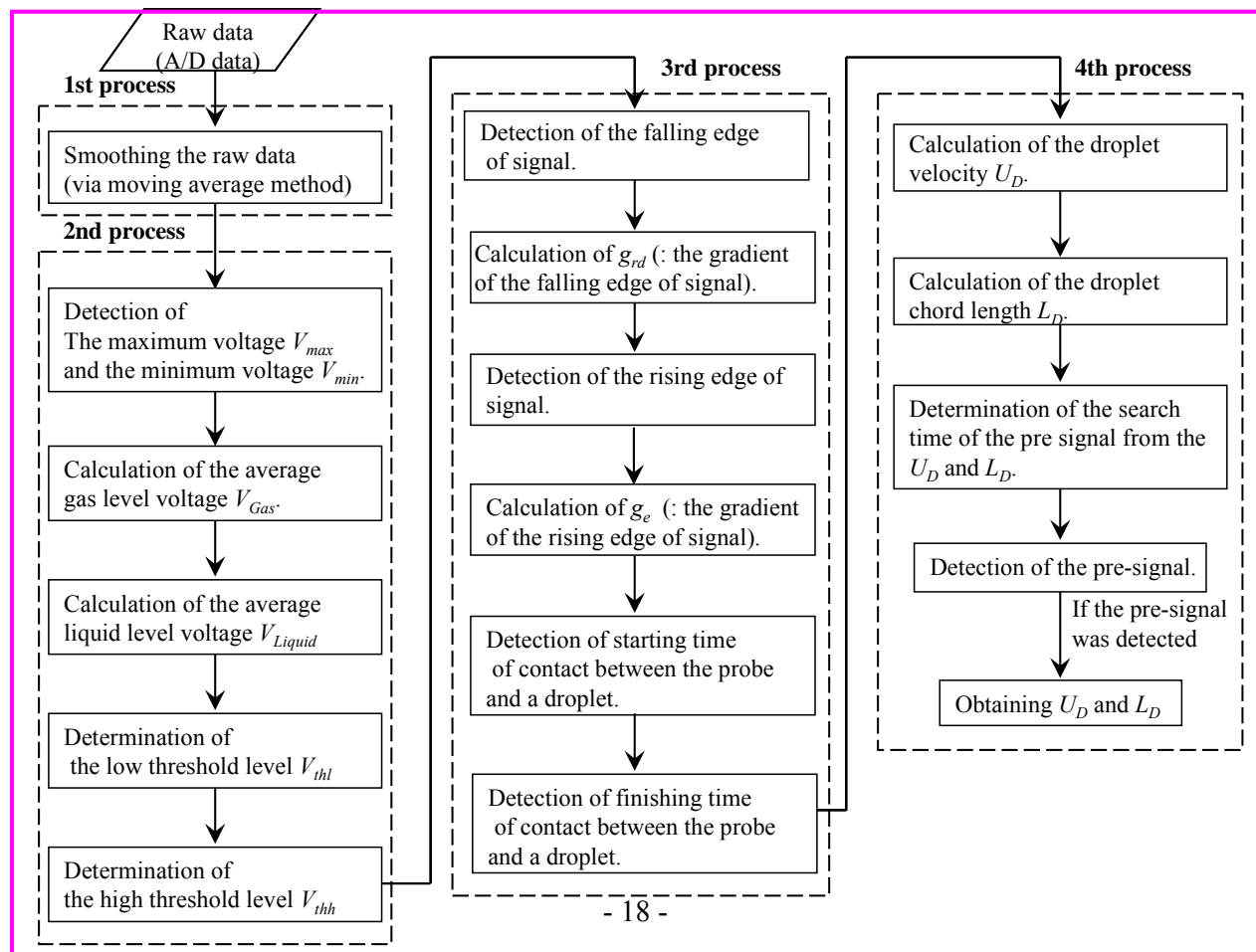

Figure 12. Flow chart of the signal processing employed.
書式変更

書式変更：フォントの色：自動 
in $2^{\text {nd }}$ process: "The maximum voltage" $\rightarrow$ "The" should not be capitalized; "low threshold level" should be "lower threshold" and "high threshold" should be "upper threshold". In $3^{\text {rd }}$ process "start time" is better than "starting time", don't use "a" before droplet or "the" before probe in "between probe and droplet" In $4^{\text {th }}$ process, don't use "the" before $U$ and L; use present tense "if pre-signal is detected"

Fig. 4: The typical S-TOP signal and snapshots corresponding to the signal showing the contact process between a sub-mm-sized droplet and the S-TOP probe.

\section{1) Smoothing process}

The raw data of the output signals are smoothed $\underline{\text { by }}$ the 25 -point moving average method to reduce the influence of high-frequency noise.

\section{2) Histogram process}

The histogram method (Sakamoto and Saito) is employed to accurately detect the output voltage levels. 
We obtain the a histogram of the output voltage signal. The threshold values which that we want can be easily extracted from peak values of the histogram. Figure 14 shows an example of the histogram of fs-ProbeFs-TOP signals. Clear fFour clear peaks (marked in the figure) are detected from the histogram. Each peak corresponds to the $\underline{a}$ stable output voltage level of the fs ProbeFs-TOP signal:

(1) Full gas--phase level (both probe tip and groove are positioned-in air) $=V_{\text {Gas }}$,

(2) Tip level (only the probe tip is positioned in the droplet) $=V_{t}$,

(3) Full lliquid_-phase level (both of the probe tip and the groove are covered within the droplet) $=V_{\text {Liquid }}$,

(4) Groove level (the groove is in the droplet) $=V_{g l}$. $\Delta$

3) The determination of thresholds

We use the thresholds to accurately detect the event time in each level as shown in figureFig.

14․․ We decide the upper $\left(V_{t h h 1}\right)$ and lower $\left(V_{t h l}\right)$ first threshold levels to detect determine the starting_time of contact between the fs_ProbeFs-TOP and a droplet. The first high threshold tevel $V_{\text {thht }}$ and the first low threshold level $V_{\text {thlt }}$ are decided.In this study, $V_{\text {thh } 1}$ was $90 \%$, and $V_{t h l l}$ was $30 \%$ of the difference in the signal amplitude between $V_{G a s}$ and $V_{t l}$. Next, the upper $\left(V_{t h h 2}\right)$ and lower $\left(V_{t h l 2}\right)$ second threshold levels are determined in order to detect the time the droplet touches the groove edge; here, the upper threshold level $V_{\text {thh } 2}$ was $90 \%$, and the lower threshold level $V_{\underline{t h l 2}}$ was $20 \%$ of the signal amplitude between $V_{l i q u i d}$ and $V_{t \underline{t}}$. Finally, the upper $\left(V_{t h h 3}\right)$ and lower $\left(V_{t h l 3}\right)$ third threshold levels are determined in order to detect the end time of contact between the fs ProbeFs-TOP and the droplet; here, the $V_{\text {thh } 3}$ was $90 \%$, and $\underline{V}_{\text {thl } l 3}$ was $20 \%$ of the signal amplitude between $V_{\text {liquid }}$ and $V_{g l}$. The second threshold level is decided in order to detect the time of the droplet touching the groove edge. The second high threshold level Vthh2 and the second low threshold level Vth12 are decided. The high threshold level $V$ thh 2 was $90 \%$, and the low threshold level Vth12 was $20 \%$ of signal amplitude between the Vliquid and Vtl. Finally, the third threshold level is decided in order to detect the finishing time of contact between the fs Probe and the droplet. The third high threshold level Vthh3 and the third low threshold level Vth13 are decided. 
$\underline{Z}^{\text {nd }}$ process: "Liquid" should not be capitalized, also don't need the paragraphing in that box. $3^{\text {rd }}$ process: suggest "upper" instead of "high" threshold and "lower" for "low"; 4 th process: suggest "start time" and "end time"; $5^{\text {th }}$ process: delete "a" from the phrases "droplet velocity", "droplet chord length"; delete "the" from"the U" 
$V_{\text {thh3 }}$-was $90 \%$, and $V_{\text {thl3 }}$-was $20 \%$ of signal amplitude between the $V_{\text {tiqutit }}$ and $V_{\text {glt }}$ - The difference of $\underline{-i n}$ detection of event time between the results of visualization and this signal processing is was less than $5.5 \%$ in all measurement cases. We consider this difference in the calculation of the event time is-as a kind of a bias difference (not a random difference); therefore ${ }_{2}$ this bias is could be removed from the measurement results viaby fs-ProbeFs-TOP.
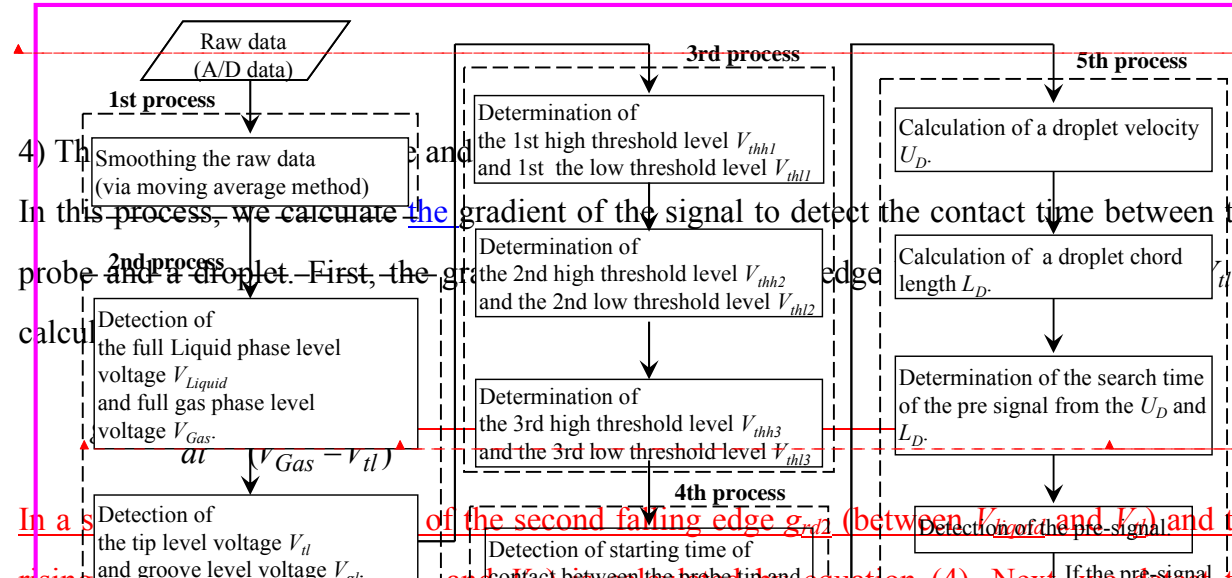

and 1st the low threshold level $V_{\text {thl }}$ I I

gradient of the signal to detect the contact time between the

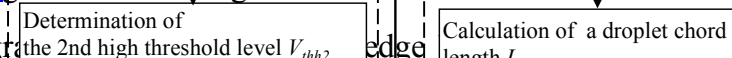
and the 2nd low threshold level $V_{\text {thi }}$.

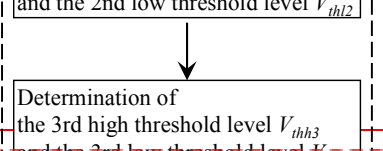

I

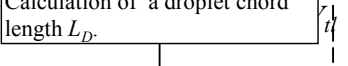
th is

and the 3rd low threshold level $V_{\overline{t h l}}$

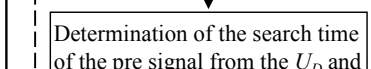

of the pre signal from the $U_{D}$ and

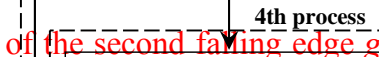

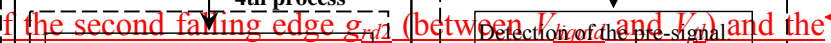
Detection of starting time of

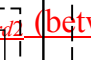

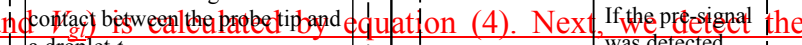
rising and groove level voltage $V_{g l}$. unuid lant deontag bets cpntat time-betreen the-prebes a

ind the droplet. We define $t_{1}^{1}$ and $\checkmark$ t of contact between the Fs-TOP tip Detection of time of arrival of the defintect-as-the-time-when-the -

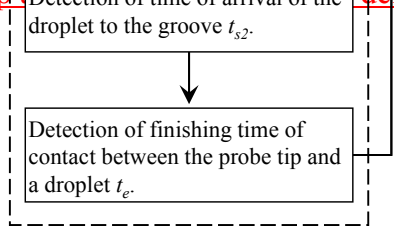

Figure 13. Flow chart of the signal processing of the fs-ProbeFs-TOP. dreplet touches the groedge. The erent time ts is defined as the intersection point of the

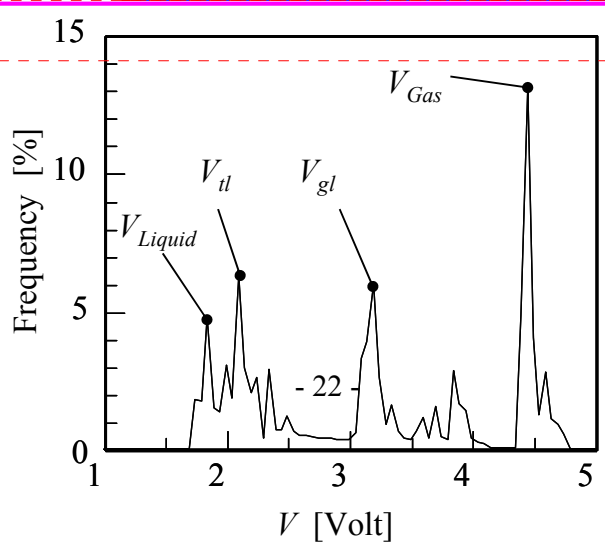

Figure 14. An examplsample of the-histograms of output voltage of fs-Probe signals.
書式変更：両端揃え

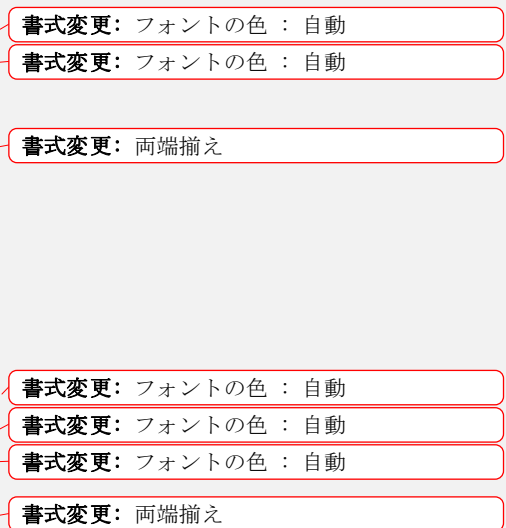

書式変更：両端揃之

コメント [KN15]: OR "the duration of the droplet touching the groove edge"?

書式変更：フォントの色：自動

書式変更：フォントの色：自動

書式変更：フォントの色：自動

書式変更：フォントの色：自動 


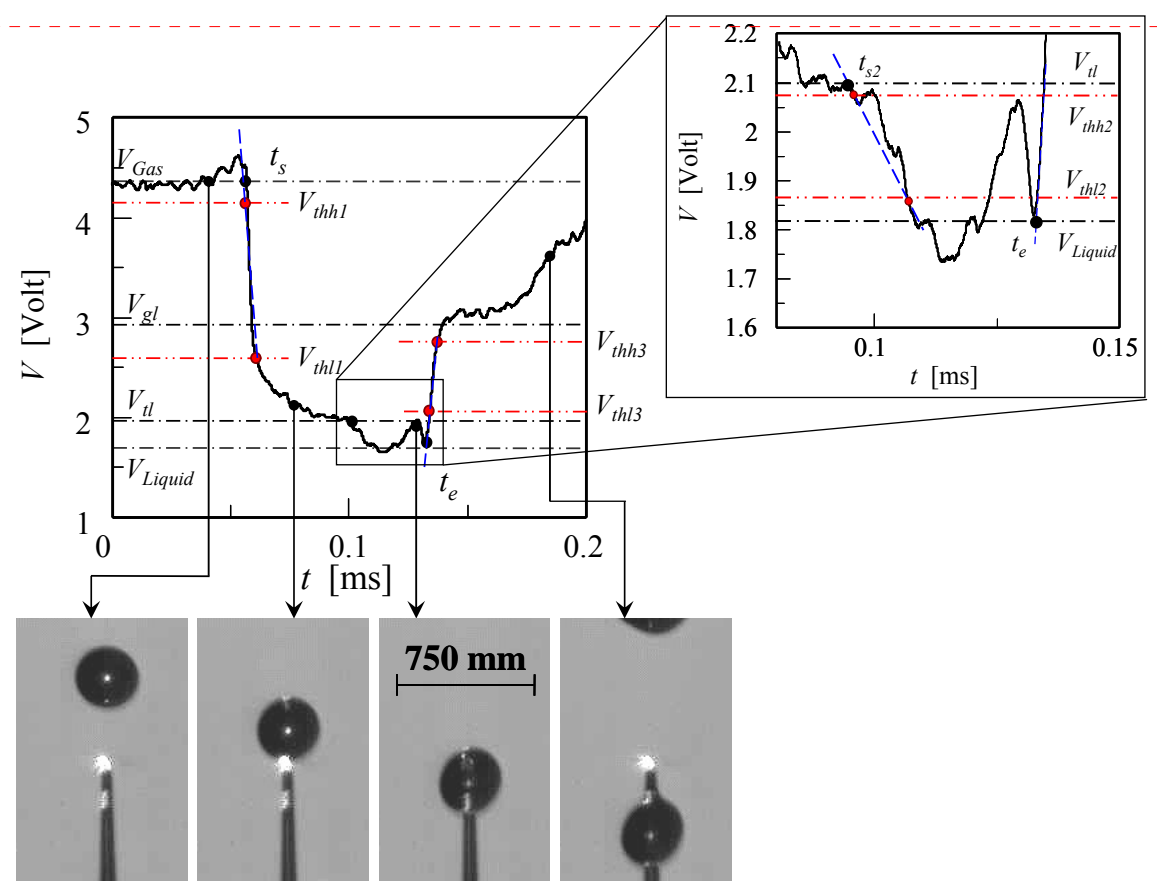

書式変更：フォントの色：自動

Figure 15. Schematic diagram of signal processing for fs-Probe. 
In a similar way, the gradient of the second falling edge $g_{*+12}$ (between $V_{\text {liquid }}$ and $V_{t t}$ ) and the

rising edge $g_{e}$ (between $V_{\text {liquid }}$ and $V_{g l}$ ) is calculated by equation (4). Next, we detect the contact time between the probe and the droplet. We define $t_{s}$-and $t_{e}$ as the beginning start and finishing end times of contact between the fs Probe tip and the droplet. The $t_{s 2}$ is defined as the time when the droplet touches the groove edge. The $t_{s 2}$ is defined as time of the droplet touching the groove edge. The event time $t_{s}$ is defined as an the intersection point of the straight line (i.e. the gradient is $g_{r d}$ ) and the gas--phase level at the first falling edge. An-The intersection point of the straight line (i.e. the gradient is $g_{r d 2}$ ) and the gas--phase level at the second falling edge is defined as the event time $t_{s 2}$. The event time $t_{e}$ is defined as an-the intersection point of the straight line (i.e. the gradient is $g_{e}$ ) and the liquid--phase level at the rising edge. As a result, we can detect event time in with high accuracy (the difference is less than $5.5 \%$ as described in the-above).

\section{5) Calculation of chord length and velocity}

書式変更：両端揃え

Finally, we calculate the droplet velocity and its chord length, and we judge the pierced position of piercing by the probe based on the pre-signal. First, we calculate the droplet velocity by equation (5):;

$$
U_{D}=\frac{L_{P}}{\left(t_{s 2}-t_{s}\right)},
$$


where $L_{P}$ is a-the distance between the tip point and the groove. The chord length $L_{D}$ is calculated from equation (6),

$$
L_{D}=U_{D} \times\left(t_{e}-t_{s}\right)
$$

Next, we judge whether the probe pierces in the centre part of the droplet by using the presignal (the algorithm is described in section 3.1.3, and the pre-signal is described in section 3.1.2).

\section{Results and Discussion}

\subsection{The S-TOP measurements.}

4.1.1 Characteristics of the S-TOP signals. The output signals in the S-TOP measurements of various diameter droplets are shown in figureFig. 16. When the sub-mm-size droplet contacts with the S-TOP, the output signal corresponding with the liquid--phase level does not stabilize. Since the S-TOP diameter is inadequate in comparison with the droplet diameter, the smallest output becomes large with a decrease in the droplet diameter. Hence, the liquid does not eover surround the sensor section of S-TOP completely. Therefore, the output voltage corresponding with-to the liquid--phase tends to be high when the droplet diameter is small. The typical output signals of the S-TOP and the corresponding pictures during itse penetration process are shown in figureFig. 17. In figureFig. 17 (a), the output signal changes in two stages for successional penetration of two droplets. The output voltage of the S-TOP signal decreases with the penetration of the first droplet. Before the signal is restored to the gas--phase level, the signal again decreases due to the penetration of the next droplet. Therefore, the output voltage of the S-TOP decreases from the liquid--phase level of the precedent-preceding droplet. We consider that this phenomenon is caused by a liquid-phase thin film which is-formed on the S-TOP surface when the first droplet hits the S-TOP. Then 七The next droplet hits the S-TOP before the removal of the liquid thin film. In addition, in these measurements the amplifier frequency of the photo-multiplier is $20 \mathrm{kHz}$. This frequency 
is too low to detect a pre-signal $;$; therefore, ${ }_{2}$ no pre-signal is observed in the sample signals in figureFig. 17 (in order to detect a pre-signal, a frequency of $200 \mathrm{kHz}$ is required).

4.1.2 Comparison between S-TOP and visualization results. Figure 18 shows the $\underline{\mathrm{a}}^{4}$ comparison between the results measured by the S-TOP and those obtained from the visualization. In this study, we measured two hundred sub-mm-size droplets to evaluate the measurement accuracy of S-TOP. The average droplet velocities via-measured by S-TOP (figureFig. 18 (a)) showed satisfactory agreement with those from the visualization,

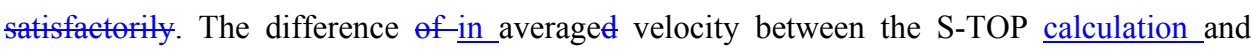
visualization is-was less than $7.2 \%$. However, the droplet velocities measured by S-TOP have a large dispersion compared with those by the visualization. The dispersion, with a ranges from $\pm 30 \%$ to $\pm 60 \%$ of droplet velocities. Furthermore, this dispersion does not depend on the droplet velocity. Figure 18 (b) shows the-a comparison of the droplet chord lengths between the S-TOP and the visualization. The average chord lengths viaby S-TOP are larger than those from the visualization. Furthermore, the dispersiontribution ranges from $30 \%$ to $60 \%$. In the visualization, we obtained the barycentric velocity of the droplets. On the other hand, the S-TOP measured the interface velocity of the droplets. Therefore, the difference between the S-TOP and the visualization results includes a kind of random differences (not $\underline{a s}$ opposed to bias differences) due to uncertain factors (e.g.g the primary surface oscillations of the droplets). It is difficult to remove-completely remove this-these random differences from the measurement results of S-TOP. Based on our results, the number of samples should be larger than 200. (In addition, in-these average results, the bias differences described in 3.1.2 are not removed.)

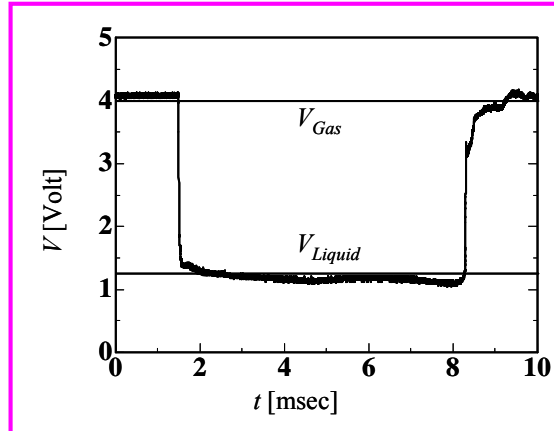

(a) $U_{D} \approx 0.8 \mathrm{~m} / \mathrm{s}, L_{D} \approx 5 \mathrm{~mm}$

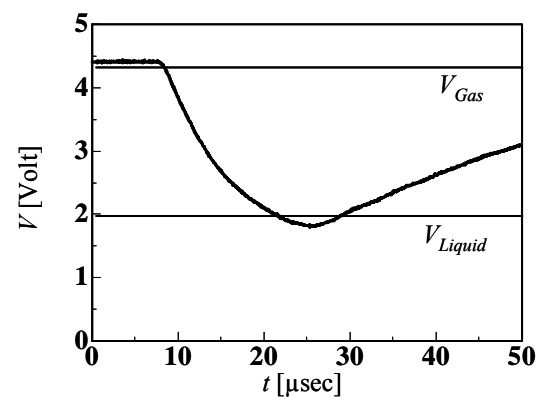

(b) $U_{D} \approx 8 \mathrm{~m} / \mathrm{s}, L_{D} \approx 130 \mu \mathrm{m}$

Figure 16. Comparison of S-TOP signals at different droplet velocities. 

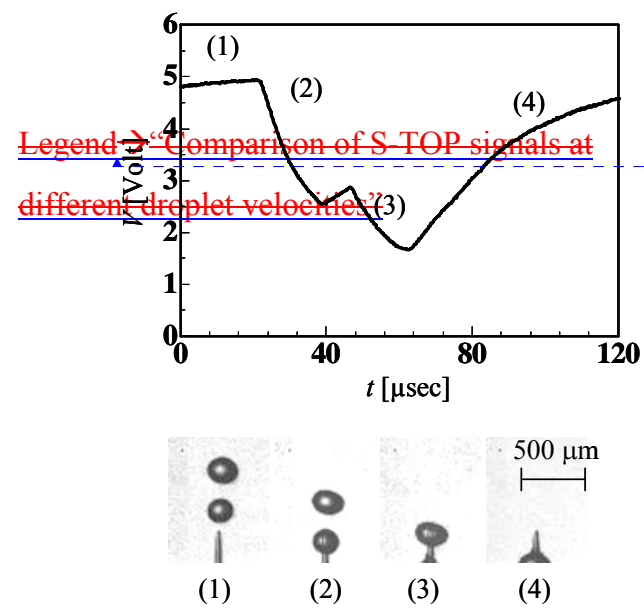
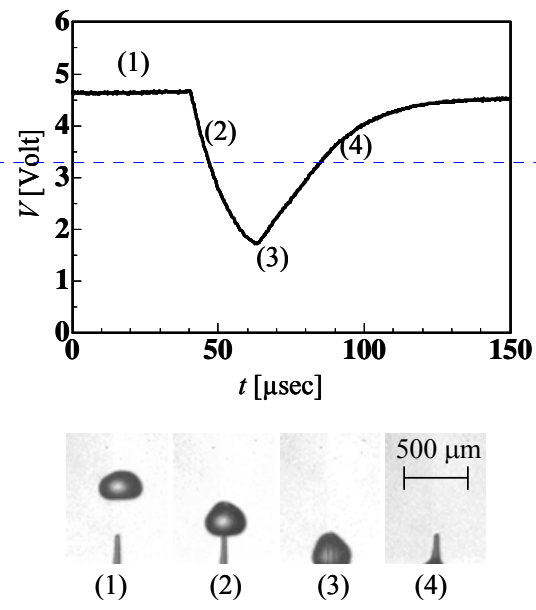

(b) A droplet is pierced by S-TOP.

(a) Droplets are pierced by S-TOP continuously

Figure 17. Typical samples of S-TOP signals. 
4.2.1 Comparison between fs ProbeFs-TOP and visualization results (mm-size droplets). The droplet velocity calculated from equation (5) and the chord lengths calculated from equation (6) were compared with those obtained from the-visualization. The droplet chord lengths from the visualization were calculated based on the projected areas. The comparison is listed in Table 1 and summarised in figureFig. 19. The fs-ProbeFs-TOP results on for droplet velocities and chord lengths are less than those from the visualization. When the droplet velocities are smaller than $2.0 \mathrm{~m} / \mathrm{s}$, the droplet velocities via by fs-ProbeFs-TOP is are approximately $5 \%$ (bias difference) smaller than those ria-by visualization. However, when the droplets velocities are higher than $2.0 \mathrm{~m} / \mathrm{s}$, those viaby fs-ProbeFs-TOP are approximately $10 \%$ (bias difference) smaller than those viaby visualization. The number of samples was random 10 of 100 . The dispersion of the other 10 samples has had the a similar distribution. The dispersion observed in the droplet velocities rangeds from $\pm 12 \%$ (at $2 \mathrm{~m} / \mathrm{s}$ ) to $\pm 20 \%$ (at $0.26 \mathrm{~m} / \mathrm{s}$ ). This dispersion decreases with increase in droplet velocity. This property is very different from the that of S-TOP (see 4.1.2).

The chord lengths measured by fs-ProbeFs-TOP include the randomness due to piercinge position (however-within the centre region of the droplets) and those due to the-surface oscillation. Furthermore, they include randomness propagated from velocities; the chord length is calculated from velocity (equation (6)). The chord lengths obtained from the visualization include randomness due to the surface oscillation. Figure 19 (b) shows the the relation ofeomparison of chord-length dispersion to droplet velocity for both between the fsProbeFs-TOP and the visualization, against the droplet velocity. The dispersion of the fsProbeFs-TOP results is wider than that of the visualization. The dispersion is not influenced by the velocity.

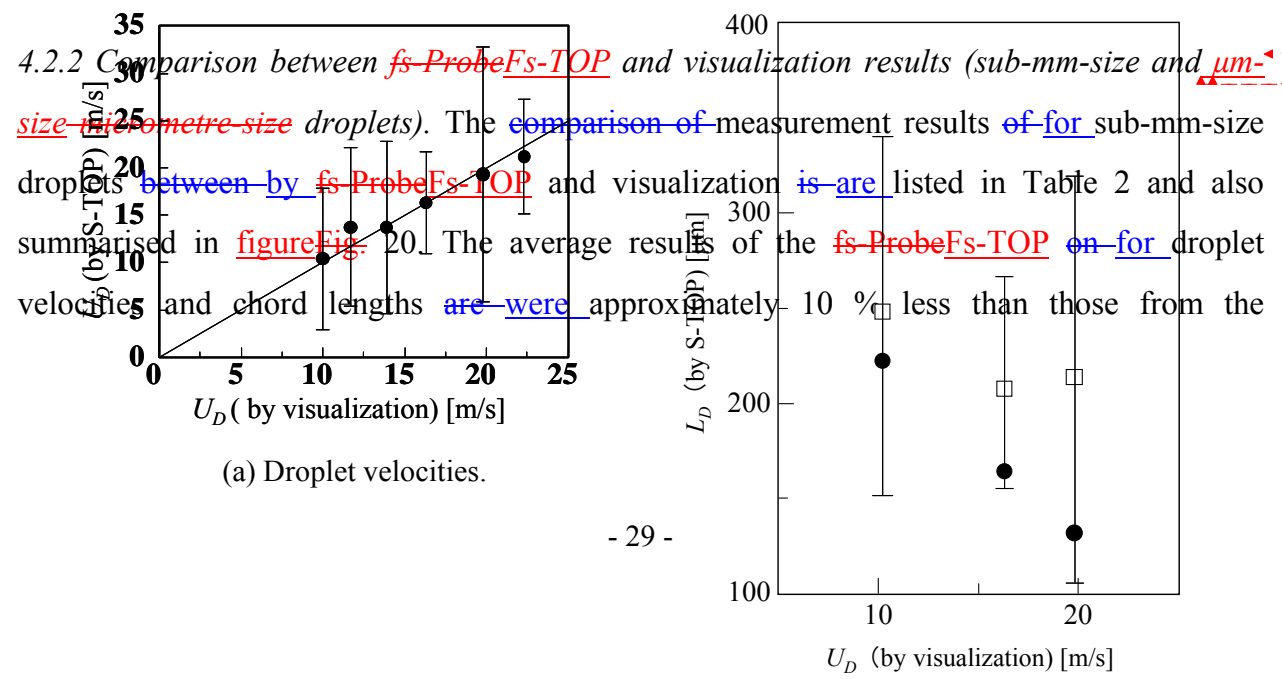

\begin{tabular}{|c|c|}
\hline 書式変更： & 両端揃え \\
\hline 書式変更： & フフォントの色：自動 \\
\hline $\begin{array}{l}\text { 書式変更： } \\
\text { 自動 }\end{array}$ & フフォント：斜体，フォントの色： \\
\hline
\end{tabular}

(b) Droplet chord lengths.

Figure 18. Differences between S-TOP and visualization results. 
visualization (this difference is a kind of bias). The velocity dispersion of fs-ProbeFs-TOP (figureFig. 20) is was wery much smaller than that wiaby S-TOP (see figureFig. 18). From figureFig. 20, the velocity dispersion of the fs ProbeFs-TOP decreases with the increase in the droplet velocity even in sub-mm-size measurements. Those tendencies of the measurement results of the sub-mm-size droplets are the same tendency of for those of the mm-size droplets. However, the dispersion of the measurement results of sub-millimetre droplets is smaller than these-that of the millimetre-size droplets. (In addition, iIn these average results, the bias differences described in 3.1.2 are not removed.)

Measurement results of the $\mu \mathrm{m}$-size-micrometre-size droplets are shown in figureFig. 21 . The results of droplet velocity via by fs-ProbeFs-TOP are smaller than those of the by visualization. Furthermore, the measurement results of the droplet chord lengths are also smaller than those from the visualization. (In these average results, the bias differences described in 3.1.2 are not removed.) Considering that S-TOP can not measure $\mu \mathrm{m}$-size-mieremetre-size droplets, the fsProbeFs-TOP has-demonstrated satisfactory performance of $\underline{\text { in }}$ measuring velocities and chord lengths of $\mu \mathrm{m}$-size-micrometre-size droplets.

\section{Conclusion}

In this paper, we describe the characteristics and performance of the Fs-TOP, a newly 


\section{Conclusion}

In this paper, we described the characteristics and performance of the S TOP and fs Probe $\left(:{ }_{2}\right.$ 書式変更：両端揃え a newly developed single single-tip optical fibre probe micro-processed by femtosecond pulse taser). We alse-compared these-the characteristics of the fs-ProbeFs-TOP and S-TOP in detail, in order to present guidelines -in order to allow researchers in various fields to selectfor effective the appropriate probe for a particular applications of these to various targets. Their €Characteristics, performance and measurement accuracies were evaluated based on the comparisons of the -probe measurement results been the S-TOP/fs Probe andwith 
visualization results. The fs ProbeFs-TOP has satisfactory performance and accuracy for measurements of $\mu \mathrm{m}$-size-micrometer-size droplets. Our investigation is summarized as follows.

For the specific purpose of reducingtion of the random errors due to piercing position, we proposed a new method using a pre-signal to detect whether the S-TOP/fs ProbeFs-TOP pierces the centre region of a droplet/bubble-by using the pre-signal. The random errors are less than $5 \%$ of the minor axes of the-droplets with $50 \mu \mathrm{m}-2 \mathrm{~mm}$ in equivalent diameter.

The forced surface deformation of the droplet when the probe touches the droplet surface is very small for droplets with $50-500 \mu \mathrm{m}$ in equivalent diameter. Hence, this surface deformation is negligible for the droplets in the abovethis diameter range.

The deformation of the a droplet pierced by the either probes is very small during measurement. In the case of sub-mm-size droplet measurements, the deformation is smaller less than $3.2 \%$ of droplets' minor axes (this-a bias difference-is a kind of bias), and in the case of $\mu$ m-size-micro-size droplet measurement ${ }_{2}$ it is smaller than $3.1 \%$ of droplets' minor axes (this difference is a kind ofa bias difference). 


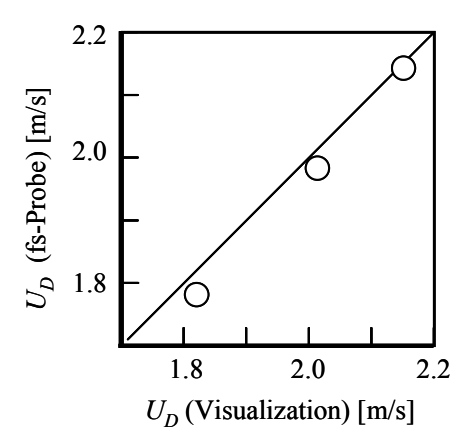

(a) Droplet velocities.

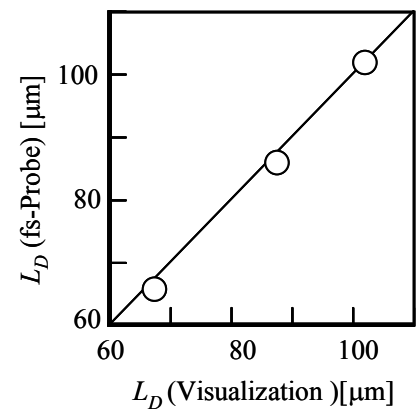

(b) Droplet chord lengths.
Figure 21. Comparison of fs-Probe measurement results of $\underline{\mu m i e r e m e t r e-s i z e}$ droplets between fs-Probe and visualization results.

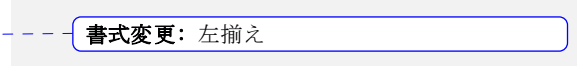

On the basis of these results, first, we described the characteristics and performance of S-TOP. In the measurement of sub-mm-size droplet, s, the difference of in averaged velocity between the S-TOP and visualization is less than $7.2 \%$ (in these average results, the bias differences described in above are not removed). However, the droplet velocities and chord lengths 
measured by S TOP have a large dispersion compared with these by the visualization. The dispersion ranges from $\pm 30 \%$ to $\pm 60 \%$ of droplet velocities. Furthermore, the average ehord lengths viaby S TOP are larger than those from the vistralization. IIn addition, those distribution ranges are also from $30 \%$ to $60 \%$. As the reason of this, the S-TOP measured the interface velocity (not barycentric velocity) of the droplets. Therefore, the difference between the S-TOP and visualization results includes a kind of random differences (not bias) due to uncertain factors (e.g. the primary surface oscillations of the droplets). It is difficult to remove completely remove this random difference from the measurement results of S-TOP. Based on our results, we suggested that the number of samples of the for S-TOP measurement have shouldto be larger than 200 to measure the droplets in obtain high-accuracy results.

Next, we described the performance and properties of the S TOP/fs-Probe by examining mmsize droplets, and sub-mm-size droplet. The dispersion of the measurement results of submm-size droplets is was smaller than those that of mm-size droplets. In the measurement of sub-mm-size droplets, the average results of the fs-Probe for on droplet velocities and chord lengths ware ere approximately $10 \%$ less than those from the visualization (this a bias difference is a kind of bias). Moreover, the velocity dispersion of by fs-Probe is was very much smaller than that via by S-TOP. The velocity dispersion of fs Probe decreases decreased with an increase in the droplet velocity, in both of the mm-size droplet and sub-mm-size droplet measurements.

In addition, we demonstrated the measurement of velocities and chord lengths of micrometresize droplets using the fs Probe. The results of for droplet velocity via by fs Probe are were smaller than those byof the visualization. Furthermore, the measurement results of the droplet chord lengths are were also smaller than those from the visualization (in these average results, the bias differences described in above are were not removed). Considering that S TOP can not measure micrometre-size droplets, the fs-Probe has demonstrated satisfactory performance of measuring velocities and chord lengths of micrometre-size droplets. As above, each optical probe (S-TOP/fs-Probe) has different kinds of characteristics. In this paper, we clarifiedy the application range of S TOP and fs Probe-quantitatively as follows;:
コメント [KN21]: Why do you use + /- here and not below? 
1) The measurement object of the S-TOP is the a-sub-mm-size droplet moving less than $5 \mathrm{~m} / \mathrm{s}$. In the cases of measuring theement of averaged velocity of sub-mm-size droplets, the desirable sample number of for the S-TOP is larger greater than 200.

2) The measurement object of the fs-Probe is the micrometre-size droplet and sub-mm-size droplets moving at over speeds of $5 \mathrm{~m} / \mathrm{s}$ or more. In the cases of measurement ofmeasuring the averaged velocity of sub-mm-size droplets, the desirable sample number of for the fsProbe is more greater than 10 .

\section{Nomenclature}

$g_{r d} \quad$ gradient of the S-TOP signal $\left(\mathrm{s}^{-1}\right)$

$L_{D} \quad$ chord length pierced by Probe $(\mathrm{mm}$ or $\mu \mathrm{m})$

$L_{P} \quad$ length between tip and groove of the fs-ProbeFs-TOP $(\mathrm{mm}$ or $\mu \mathrm{m})$

$t$ time (s or ms)

$V \quad$ output of a photo multiplier (V)

$U_{D} \quad$ interface velocity $(\mathrm{m} / \mathrm{s}$ or $\mathrm{mm} / \mathrm{s})$

\section{Greek symbol}

$\alpha \quad$ proportionality coefficient (m)

\section{Subscripts}

at groove

$\mathrm{f} \quad$ end of contact

Gas gas phase level

Liquid liquid phase level

min minimum output

s start of contact

\section{References}


Abuaf N-, Jones O- C- Jr- and Zimmer A-, 1978, Optical probe for local void fraction and interface velocity measurements, Review, of Sci,entifie Instruments, Vol.49, 1090__1094.

Cartellier A-, 1990, Optical probes for local void fraction measurements: Characterization of performance, Rev_iew of Sci, entific Instruments, Vol.61; 874-_886-

Cartellier A- and Achard- J- L-, 1991, Local phase detection probes in fluid/fluid two-phase flows, Rev.iew of Sci.entific Instruments, , Vol. 62, 279-_303.

Cartellier A-, 1992, Simultaneous void fraction measurement, bubble velocity, and size estimate using a single optical probe in gas-liquid two-phase flows, Rev Instrum.ents, Vol. 63. 5442-_5453.

Cartellier A-, 1998, Measurement of gas phase characteristics using new monofibre optical probes and real-time signal processing, Nuctearl. Eng.ineering and-Des.ign, Vol.184, 393408-

Clark N- N-, Liu W- and Turton R-, 1996-, Data interpretation techniques for inferring bubble size distribution from probe signals in fluidized systems, Powder Technotlegy, Vol. 88, 179188 -

Clark N- N- and Turton $\mathrm{R}_{-}, 1988$; Chord length distributions related to bubble size distributions in multiphase flows, Int.ernational J.eurnal of Multiphase. Flow, Vol.14, 413424.

Hong $M_{2,-,}$ Cartellier $A_{-,}$and Hopfinger $E_{-} J_{-,}$2004, Characterization of phase detection optical probes for the measurement of the dispersed phase parameters in sprays; Int.ernational J.eutrnal of Multiphase. Flow; 30 615-_648- 
Mudde R F and Saito T 2001 Hydrodynamical similarities between bubble column and

bubbly pipe flow J. Fluid Mech. 203-228

Saito T- and Mudde R-F., 2001, Performance of 4-tip Optical Fibre Probe and Bubble

Characterizations by the Probe in Turbulent Bubbly Flows, Proc.eedings of

Internationalernational Conf.erence on Multiphase Flow 2001, Paper NNo.111, in CD-ROM-

Saito $\mathrm{T}_{-}$, Ishigaki $\mathrm{Y}_{-,}$and Mizuno $\mathrm{Y}_{\overline{-}}$, 2004, Measurement and Characterization of Bubbles in a Bubble Column using 4-Tip Optical Fibre Probe; Proc.eedings of International Conf.erence on Multiphase Flow 2004, Paper NNo.113, in CD-ROM-

Saito T-, Kitamura M-, Kajishima T-, and Hatano $H_{-,}$1999, Measurement of bubble dynamics by an optical fibre probe (1st Report), Influence of an optical fibre probe on bubble interfacial motion, Trans.action of Japan Soc_iety of Mech_anical Eng.ineers Series_B; 65 -2619-_2626 (in Japanese)-

Saito $T_{-,}$and Kajishima $T_{-,}$2002, Measurement of bubble dynamics by an optical fibre probe (2nd Report), simultaneous measurement of interfacial velocity and chord length of a bubbleTrans action of Japan Soc.iety of Mech, anical Eng ineers Series-B, 68 -2719- 2725 (in Japanese)-

$\underline{\text { Saito T } 2000 \text { Japanese Patent No. } 3018178}$

Saito T, 2007a Japanese Patent, Patent application number 177607,2007.

Saito T, Japanese Patent, No. 3018178, 2000.

Saito T, 2007, $\underline{b}$ Tiny Bubbles and Droplets Measurement viaby Optical Fibre Probe Processed Using a Femtosecond Pulse Laser, Proc.eedings of International Conf.erence on Multiphase Flow 2007, Key note lecture, Paper №no. KN 10, in CD-ROM- 
Saito $T, 2007 \underline{\mathrm{c}}$, Bubble and droplets measurement wiaby optical fibre probe processed by femtosecond pulse laser, Proc.eedings of International Conf.erence on Nuclear Engineering 16. Paper Nno. 48470, in CD-ROM 


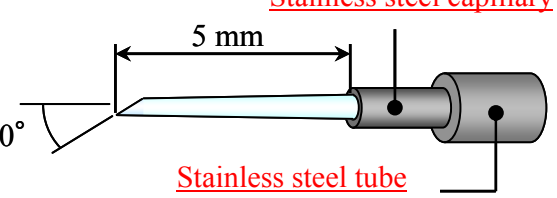

Figure 1. Structure of S-TOP. 


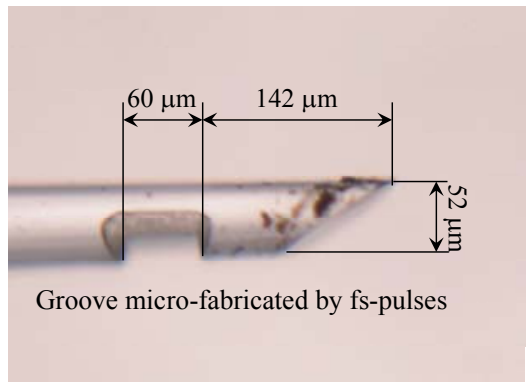

Figure 2. Close-up photograph of $\mathrm{fs}$ ProbeFs-TOP for sub-mm-size droplets. 


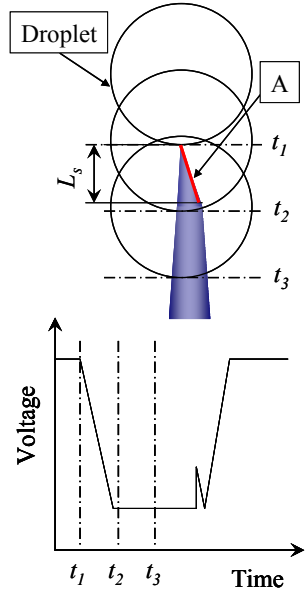

(a) S-TOP

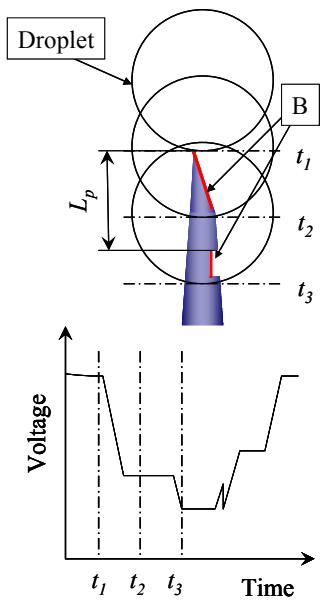

(b) fs-Probe

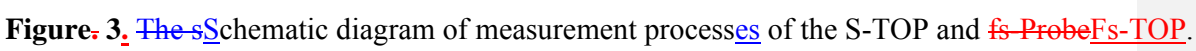


(e)

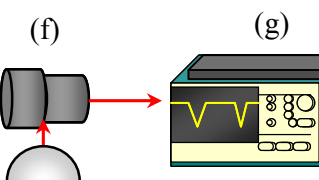

(a)
0

$\longrightarrow$ (c)

(d)

Figure 4. Optics.

Figure 4. Optics.

(a) Laser diode, (b) Beamsplitter, (c) Objective lens, (d) Optical fibre probe, (e) Polarizer,
更：単語の途中で改行寸る

書式変更：中央揃え 


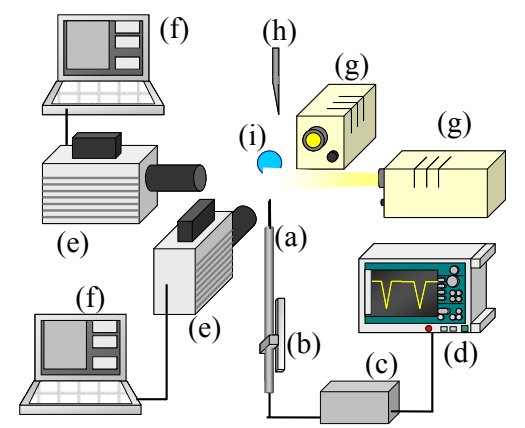

(a) Probe, (b) Optical stages, (c) Optics,

-(d) Recorder, (e) Highspeed video camera, (f) PC, (g) Halogen light, (h) Needle, (i) Droplet Fiqure 5. Experimental

(a) Probe, (b) Optical stages, (c) Optics, (d) Recorder, (e) High-speed

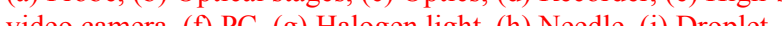




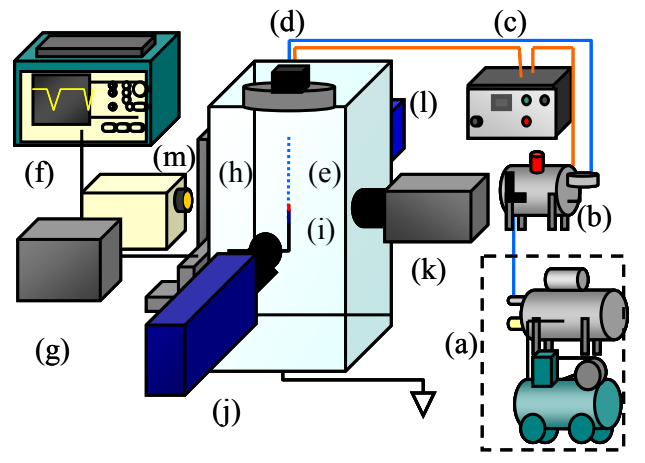

(a) Pressurization source, (b) Water tank, (c) Pressure controller, (d) Electromagnetic valve, (e) Piezo nozzle, (f) Digital oscilloscope, (g) Optical system, (h) 3-axis unit, (i) S-TOP, (j) High-speed video camera 1, (k) High-speed video camera 2, (l) Strobe light, (m) Halogen light source.

Figure 6. Experimental setup for measurement of sub-millimetre-size droplets. 


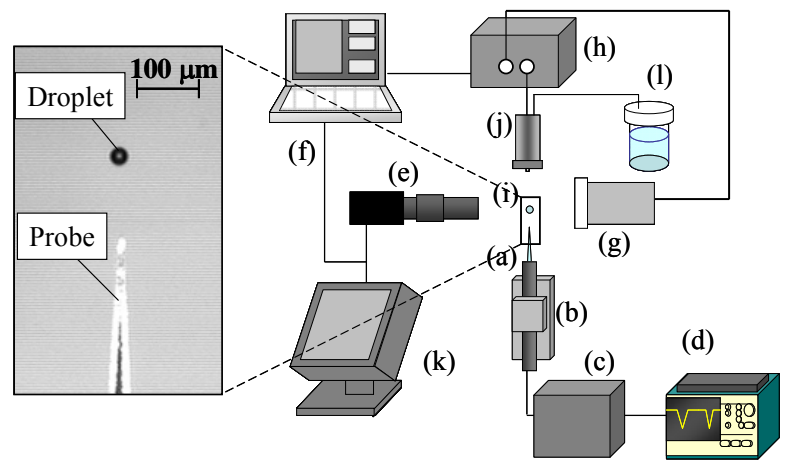

(a) Probe, (b) Optical stages, (c) Optical system, (d) Digital oscilloscope,

(e) High-speed video camera, (f) PC, (g) Strobe light, (h) Piezoelectric ink jet nozzle,

(i) Droplet,

(i) Controller, (k) Monitor, (l) Water tank

Figure 7. Experimental setup for measurement of $\mu$ micrometre-size droplets. (a) Probe, (b) Optical stages, (c) Optical system, (d) Digital oscilloscope,

(e) High-speed video camera, (f) PC, (g) Strobe light, (h) Piezoelectric ink jet nozzle, (i) Droplet,

(j) Controller, (k) Monitor, (l) Water tank 


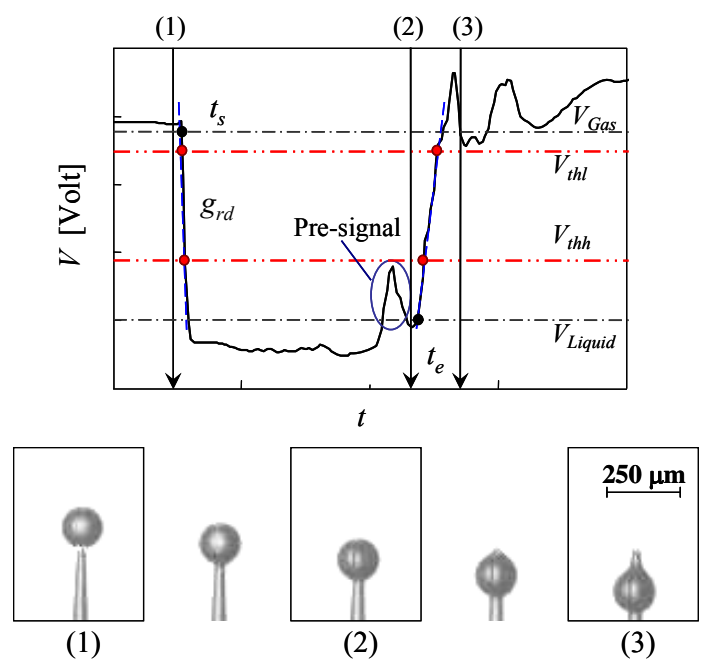

Figure 8. A typical signal in for droplet measurements viaby S- 


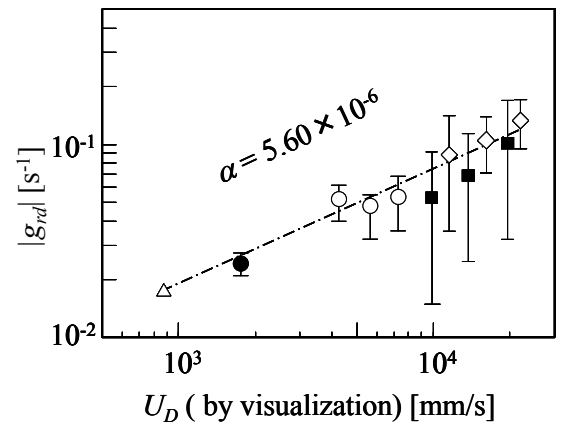

$\diamond$ Sub-mm-size droplets $\left(L_{D}=250 \pm 60 \mu \mathrm{m}\right)$

- Sub-mm-size droplets $\left(L_{D}=300 \pm 60 \mu \mathrm{m}\right)$ ○ Sub-mm-size droplets $\left(L_{D}=500 \pm 60 \mu \mathrm{m}\right)$

- Medium-size droplets $\left(L_{D}=2500 \pm 30 \mu \mathrm{m}\right)$ $\triangle$ Medium-size droplets $\left(L_{D}=5000 \pm 60 \mu \mathrm{m}\right)$

Figure 9. The relationship between $g_{r d}$ and $U_{D}$ (visualization) rearranged by using $\alpha$ of 

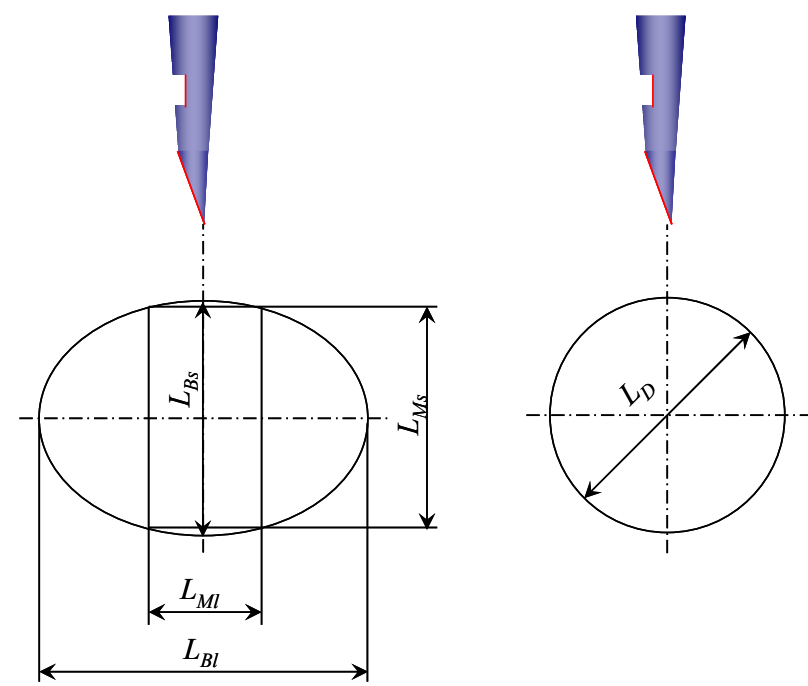

Figure 10. Schematic drawings of relationship between pierce region and measurement chord length. 


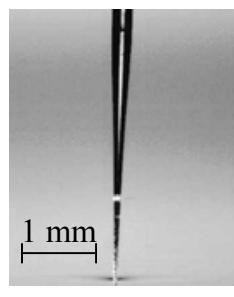

$t=0$ [ms]

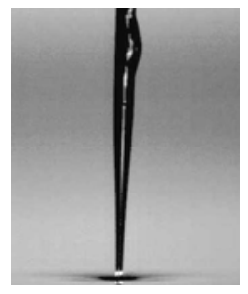

$t=2[\mathrm{~ms}]$

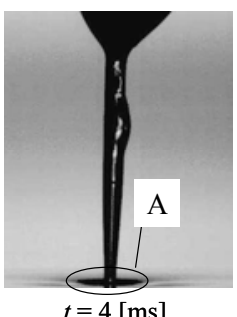

$t=4$ [ms]

(a)(b) Snapshots: The fs-Probe touching the-a flat interface at-a low velocity (100 $\mathrm{mm} / \mathrm{s})$;

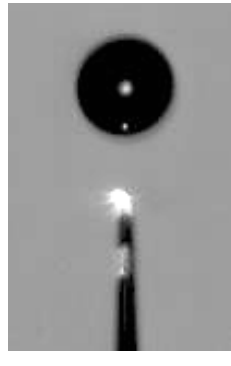

$t=0[\mu \mathrm{s}]$

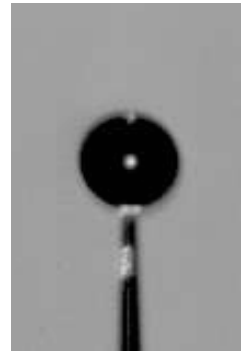

$t=2[\mu \mathrm{s}]$

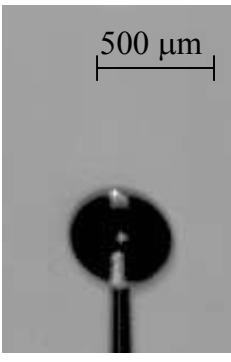$$
t=4[\mu \mathrm{s}]
$$

(b) Snapshots: The fs-Probe touching a sub-mm-size droplet moving at a high velocity $(10 \mathrm{~m} / \mathrm{s})$;

Figure 11. Snapshots of touching process under different conditions. 


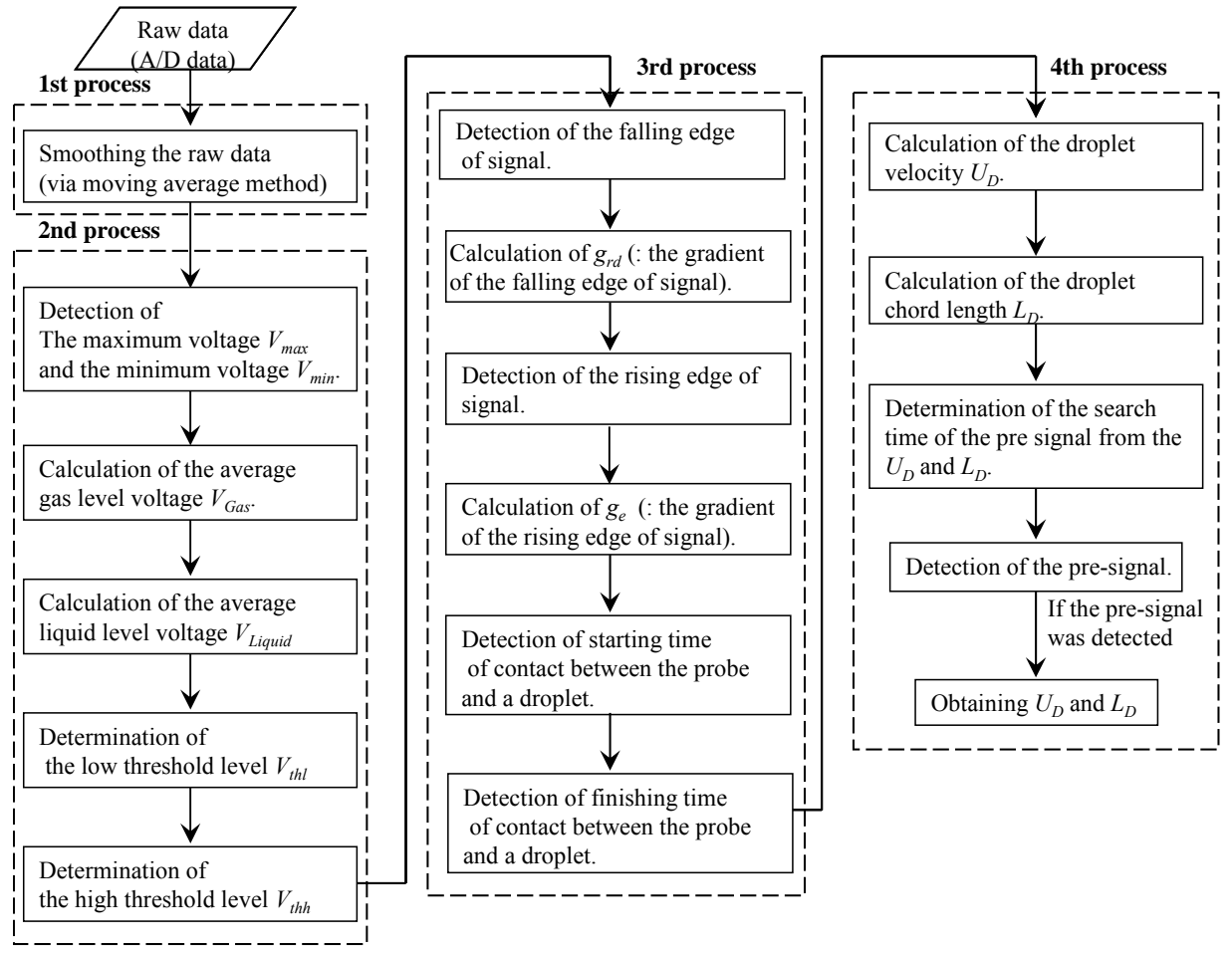

Figure 12. Flow chart of the signal processing employed. 


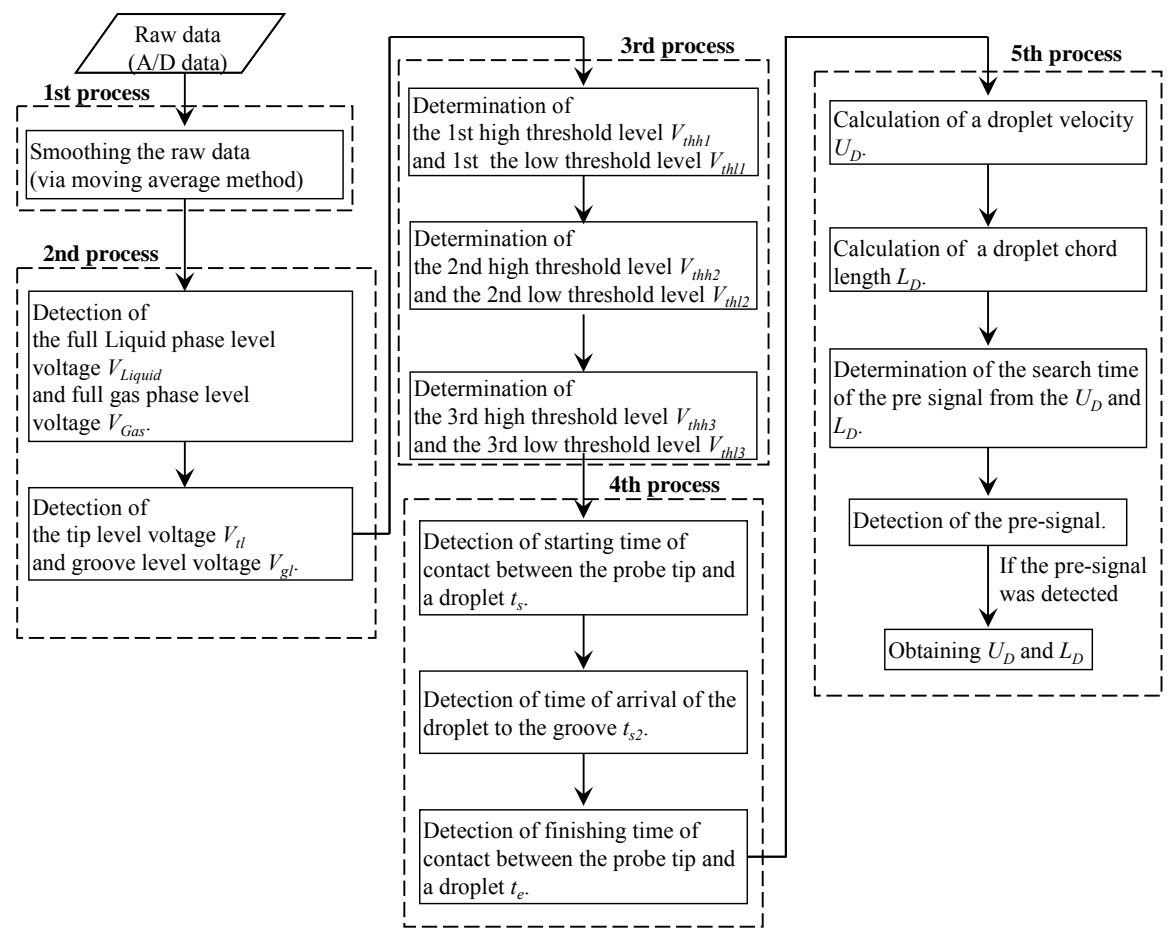

Figure 13. Flow chart of the signal processing of the fs ProbeFs-TOP. 


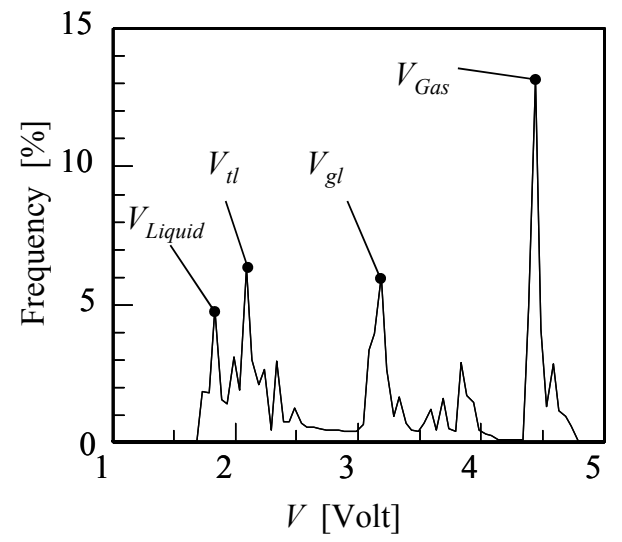

Figure 14. An examplsample ef the histograms of output voltage of fs-Probe signals. 


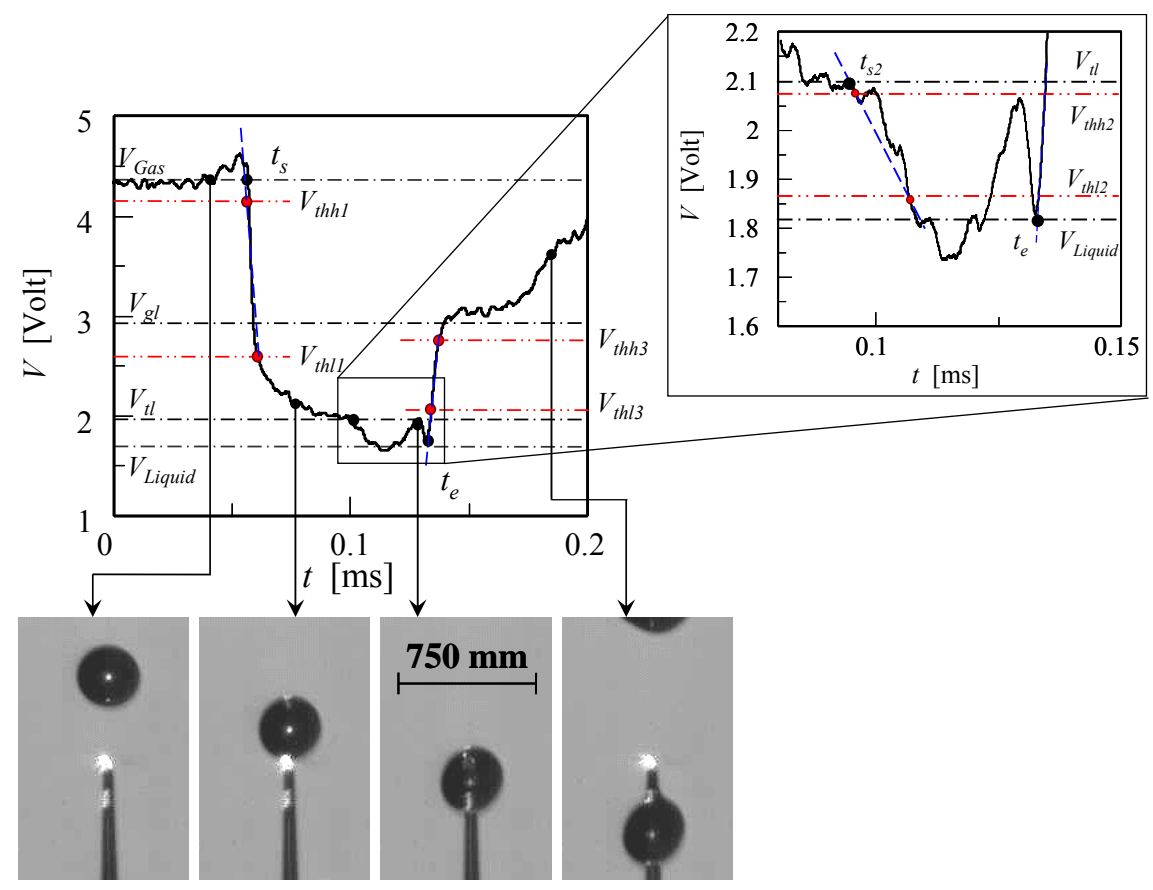

Figure 15. Schematic diagram of signal processing for fs-Probe. 

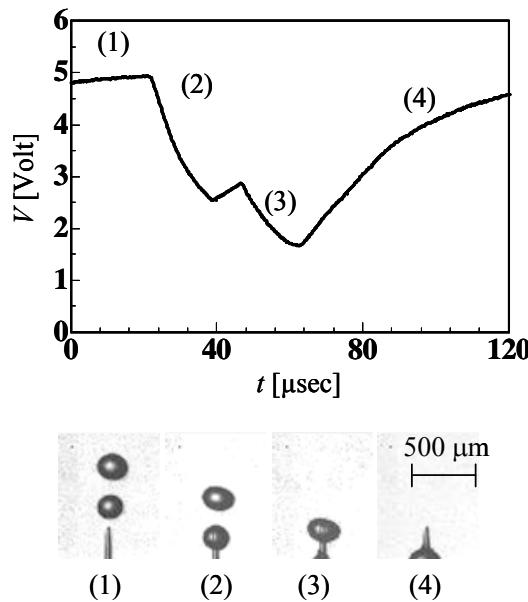
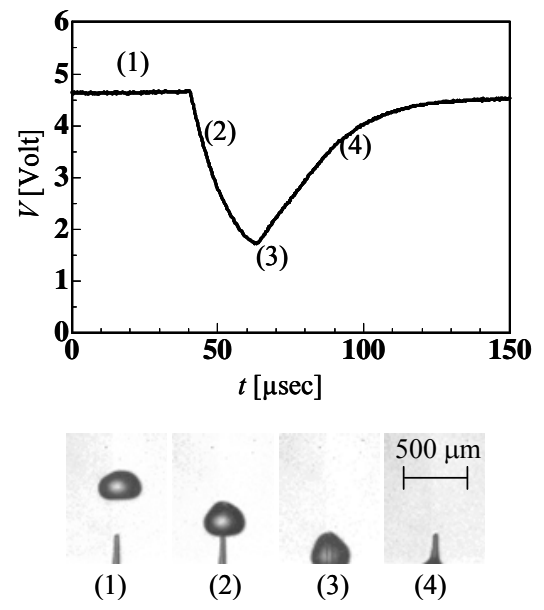

(a) Droplets are pierced by S-TOP continuously. $\quad$ (b) A droplet is pierced by S-TOP.

Figure 17. Typical samples of S-TOP signals. 


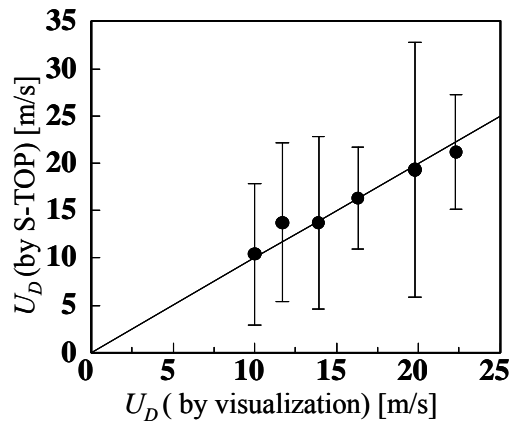

(a) Droplet velocities.

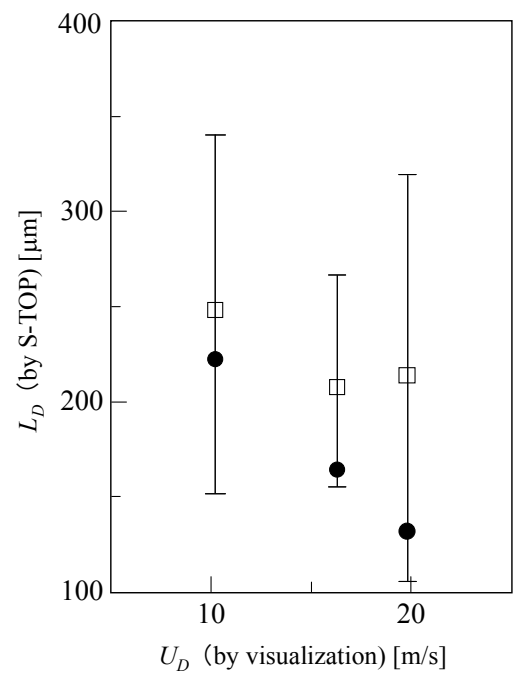

(b) Droplet chord lengths.

Figure 18. Differences between S-TOP and visualization results. 
Table 1. Differences between fs-ProbeFs-TOP and visualization results (mm-size droplets).

(a) Average droplet velocities

(b) Average droplet chord lengths

\begin{tabular}{ccc}
\hline $\begin{array}{c}\text { Visualization } \\
{[\mathrm{m} / \mathrm{s}]}\end{array}$ & $\begin{array}{c}\text { fs-Probe } \\
{[\mathrm{m} / \mathrm{s}]}\end{array}$ & $\begin{array}{c}\text { Differences } \\
{[\%]}\end{array}$ \\
\hline 0.279 & 0.271 & -2.8 \\
\hline 0.681 & 0.653 & -4.3 \\
\hline 1.069 & 1.040 & -2.8 \\
\hline 1.434 & 1.350 & -6.2 \\
\hline 1.776 & 1.691 & -5.0 \\
\hline 2.210 & 1.989 & -11.1 \\
\hline
\end{tabular}

\begin{tabular}{cccc}
\hline $\begin{array}{c}\text { Velocities } \\
{[\mathrm{m} / \mathrm{s}]}\end{array}$ & $\begin{array}{c}\text { Visualization } \\
{[\mathrm{mm}]}\end{array}$ & $\begin{array}{c}\text { fs-Probe } \\
{[\mathrm{mm}]}\end{array}$ & $\begin{array}{c}\text { Differences } \\
{[\%]}\end{array}$ \\
\hline 0.28 & 2.89 & 2.48 & -16.3 \\
\hline 0.68 & 2.65 & 2.77 & 4.2 \\
\hline 1.07 & 2.77 & 2.53 & -9.5 \\
\hline 1.43 & 2.20 & 2.48 & 11.4 \\
\hline 1.78 & 2.79 & 2.68 & -4.1 \\
\hline 2.21 & 2.21 & 2.04 & -8.6 \\
\hline
\end{tabular}




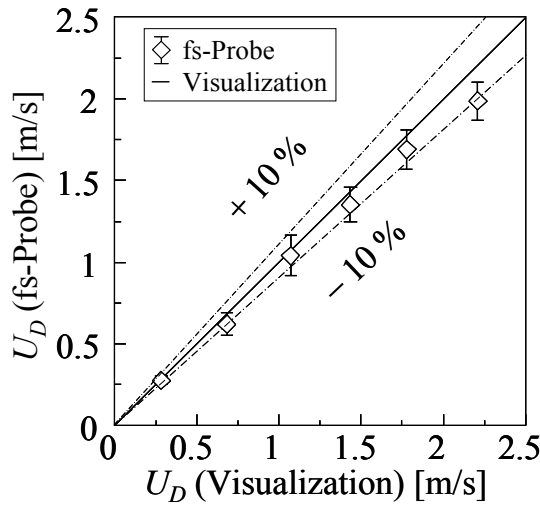

(a) Droplets velocity

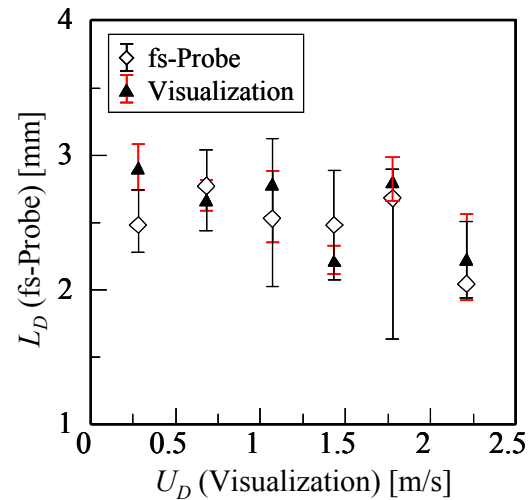

(b) Chord length variance against the droplet velocity.

Figure 19. Comparison between fs-ProbeFs-TOP and visualization results (mm-size droplets). 


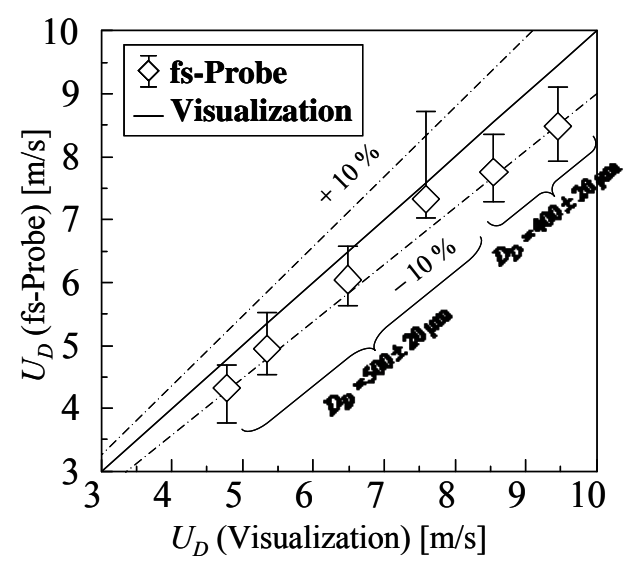

Figure 20. Comparison of fs-ProbeFs-TOP measurement results

of sub-millimetre-size droplets between 
Table 2. Differences of measurement results of sub-millimetre-size droplets

between fs ProbeFs-TOP and visualization

\begin{tabular}{ccc}
\hline $\begin{array}{c}\text { Visualization } \\
{[\mathrm{m} / \mathrm{s}]}\end{array}$ & $\begin{array}{c}\text { Fs-TOP } \\
{[\mathrm{m} / \mathrm{s}]}\end{array}$ & $\begin{array}{c}\text { Differences } \\
{[\%]}\end{array}$ \\
\hline 4.77 & 4.32 & -9.5 \\
\hline 5.35 & 4.95 & -7.5 \\
\hline 6.49 & 6.05 & -6.8 \\
\hline 7.59 & 7.33 & -3.5 \\
\hline 8.55 & 7.76 & -9.2 \\
\hline 9.46 & 8.49 & -10.3 \\
\hline
\end{tabular}

書式変更：フォント：太字 


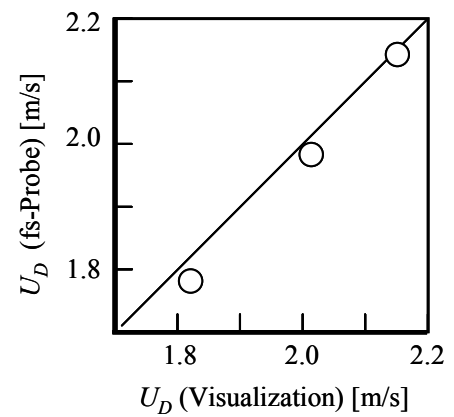

(a) Droplet velocities.

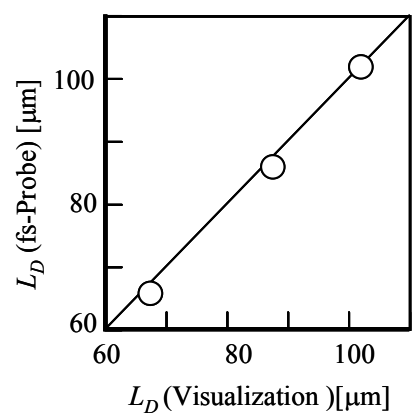

(b) Droplet chord lengths.

Figure 21. Comparison of fs-Probe measurement results of $\underline{\mu \text { micrometre-size }}$ droplets been fs-Probe-and visualization results.

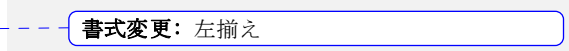




\begin{tabular}{|c|c|c|}
\hline ページ - 3 -: [1] 書式変更 & T. Saito & $2009 / 06 / 26 \quad 23: 43: 00$ \\
\hline \multicolumn{3}{|c|}{ フォント : Times New Roman } \\
\hline ページ - 3 -: [1] 書式変更 & T. Saito & $2009 / 06 / 26 \quad 23: 43: 00$ \\
\hline \multicolumn{3}{|c|}{ フォント: Times New Roman } \\
\hline ページ - 3 -: [2] 書式変更 & T. Saito & $2009 / 06 / 26 \quad 23: 43: 00$ \\
\hline \multicolumn{3}{|c|}{ フォント : Times New Roman } \\
\hline ページ - 3 -: [2] 書式変更 & T. Saito & $2009 / 06 / 26 \quad 23: 43: 00$ \\
\hline \multicolumn{3}{|c|}{ フォント : Times New Roman } \\
\hline ページ - 3 -: [2] 書式変更 & T. Saito & $2009 / 06 / 26 \quad 23: 43: 00$ \\
\hline \multicolumn{3}{|c|}{ フォント : Times New Roman } \\
\hline ページ - 3 -: [2] 書式変更 & T. Saito & $2009 / 06 / 26 \quad 23: 43: 00$ \\
\hline \multicolumn{3}{|c|}{ フォント : Times New Roman } \\
\hline ページ - 3 -: [2] 書式変更 & T. Saito & $2009 / 06 / 26 \quad 23: 43: 00$ \\
\hline \multicolumn{3}{|c|}{ フォント: Times New Roman } \\
\hline ページ - 3 -: [2] 書式変更 & T. Saito & $2009 / 06 / 26 \quad 23: 43: 00$ \\
\hline \multicolumn{3}{|c|}{ フォント : Times New Roman } \\
\hline ページ - 3 -: [2] 書式変更 & T. Saito & $2009 / 06 / 26 \quad 23: 43: 00$ \\
\hline \multicolumn{3}{|c|}{ フォント : Times New Roman } \\
\hline ページ - 3 -: [2] 書式変更 & T. Saito & $2009 / 06 / 2623: 43: 00$ \\
\hline \multicolumn{3}{|c|}{ フォント : Times New Roman } \\
\hline ページ - 3 -: [2] 書式変更 & T. Saito & $2009 / 06 / 26 \quad 23: 43: 00$ \\
\hline
\end{tabular}

フォント : Times New Roman 


\begin{tabular}{|c|c|c|}
\hline ページ - 3 -: [2] 書式変更 & T. Saito & $2009 / 06 / 26 \quad 23: 43: 00$ \\
\hline \multicolumn{3}{|c|}{ フォント : Times New Roman } \\
\hline ページ - 3 -: [2] 書式変更 & T. Saito & $2009 / 06 / 26 \quad 23: 43: 00$ \\
\hline \multicolumn{3}{|c|}{ フォント: Times New Roman } \\
\hline ページ - 3 -: [2] 書式変更 & T. Saito & $2009 / 06 / 26 \quad 23: 43: 00$ \\
\hline \multicolumn{3}{|c|}{ フォント : Times New Roman } \\
\hline ページ - 3 -: [2] 書式変更 & T. Saito & $2009 / 06 / 26 \quad 23: 43: 00$ \\
\hline \multicolumn{3}{|c|}{ フォント : Times New Roman } \\
\hline ページ - 3 -: [2] 書式変更 & T. Saito & $2009 / 06 / 26 \quad 23: 43: 00$ \\
\hline \multicolumn{3}{|c|}{ フォント: Times New Roman } \\
\hline ページ - 3 -: [2] 書式変更 & T. Saito & $2009 / 06 / 26 \quad 23: 43: 00$ \\
\hline \multicolumn{3}{|c|}{ フォント : Times New Roman } \\
\hline ページ - 3 -: [2] 書式変更 & T. Saito & $2009 / 06 / 26 \quad 23: 43: 00$ \\
\hline \multicolumn{3}{|c|}{ フォント : Times New Roman } \\
\hline ページ - 3 -: [2] 書式変更 & T. Saito & $2009 / 06 / 26 \quad 23: 43: 00$ \\
\hline \multicolumn{3}{|c|}{ フォント: Times New Roman } \\
\hline ページ - 3 -: [2] 書式変更 & T. Saito & $2009 / 06 / 26 \quad 23: 43: 00$ \\
\hline \multicolumn{3}{|c|}{ フォント : Times New Roman } \\
\hline ページ - 3 -: [2] 書式変更 & T. Saito & $2009 / 06 / 26 \quad 23: 43: 00$ \\
\hline \multicolumn{3}{|c|}{ フォント : Times New Roman } \\
\hline ページ - 3 -: [2] 書式変更 & T. Saito & $2009 / 06 / 26 \quad 23: 43: 00$ \\
\hline
\end{tabular}

フォント : Times New Roman 


\begin{tabular}{|c|c|c|}
\hline ページ - 3 -: [2] 書式変更 & T. Saito & $2009 / 06 / 26 \quad 23: 43: 00$ \\
\hline \multicolumn{3}{|c|}{ フォント : Times New Roman } \\
\hline ページ - 3 -: [2] 書式変更 & T. Saito & $2009 / 06 / 26 \quad 23: 43: 00$ \\
\hline \multicolumn{3}{|c|}{ フォント: Times New Roman } \\
\hline ページ - 3 -: [2] 書式変更 & T. Saito & $2009 / 06 / 26 \quad 23: 43: 00$ \\
\hline \multicolumn{3}{|c|}{ フォント : Times New Roman } \\
\hline ページ - 3 -: [2] 書式変更 & T. Saito & $2009 / 06 / 26 \quad 23: 43: 00$ \\
\hline \multicolumn{3}{|c|}{ フォント : Times New Roman } \\
\hline ページ - 3 -: [2] 書式変更 & T. Saito & $2009 / 06 / 26 \quad 23: 43: 00$ \\
\hline \multicolumn{3}{|c|}{ フォント: Times New Roman } \\
\hline ページ - 3 -: [2] 書式変更 & T. Saito & $2009 / 06 / 26 \quad 23: 43: 00$ \\
\hline \multicolumn{3}{|c|}{ フォント : Times New Roman } \\
\hline ページ - 3 -: [2] 書式変更 & T. Saito & $2009 / 06 / 26 \quad 23: 43: 00$ \\
\hline \multicolumn{3}{|c|}{ フォント : Times New Roman } \\
\hline ページ - 3 -: [2] 書式変更 & T. Saito & $2009 / 06 / 26 \quad 23: 43: 00$ \\
\hline \multicolumn{3}{|c|}{ フォント: Times New Roman } \\
\hline ページ - 3 -: [2] 書式変更 & T. Saito & $2009 / 06 / 26 \quad 23: 43: 00$ \\
\hline \multicolumn{3}{|c|}{ フォント : Times New Roman } \\
\hline ページ - 3 -: [2] 書式変更 & T. Saito & $2009 / 06 / 26 \quad 23: 43: 00$ \\
\hline \multicolumn{3}{|c|}{ フォント : Times New Roman } \\
\hline ページ - 3 -: [2] 書式変更 & T. Saito & $2009 / 06 / 26 \quad 23: 43: 00$ \\
\hline
\end{tabular}

フォント : Times New Roman 


\begin{tabular}{|c|c|c|}
\hline ページ - 3 -: [2] 書式変更 & T. Saito & $2009 / 06 / 26 \quad 23: 43: 00$ \\
\hline \multicolumn{3}{|c|}{ フォント : Times New Roman } \\
\hline ページ - 3 -: [3] 書式変更 & T. Saito & 2009/11/05 11:54:00 \\
\hline \multicolumn{3}{|l|}{ フォントの色 : 自動 } \\
\hline ページ - 3 -: [3] 書式変更 & T. Saito & 2009/11/05 11:54:00 \\
\hline \multicolumn{3}{|l|}{ フォントの色: 自動 } \\
\hline ページ - 3 -: [3] 書式変更 & T. Saito & 2009/11/05 11:54:00 \\
\hline \multicolumn{3}{|l|}{ フォントの色: 自動 } \\
\hline ページ - 3 -: [3] 書式変更 & T. Saito & 2009/11/05 11:54:00 \\
\hline \multicolumn{3}{|l|}{ フォントの色：自動 } \\
\hline ページ - 3 -: [3] 書式変更 & T. Saito & 2009/11/05 11:54:00 \\
\hline \multicolumn{3}{|l|}{ フォントの色: 自動 } \\
\hline ページ - 3 -: [3] 書式変更 & T. Saito & $2009 / 11 / 05 \quad 11: 54: 00$ \\
\hline \multicolumn{3}{|l|}{ フォントの色: 自動 } \\
\hline ページ - 3 -: [3] 書式変更 & T. Saito & $2009 / 11 / 05 \quad 11: 54: 00$ \\
\hline \multicolumn{3}{|l|}{ フォントの色：自動 } \\
\hline ページ - 3 -: [3] 書式変更 & T. Saito & $2009 / 11 / 05 \quad 11: 54: 00$ \\
\hline \multicolumn{3}{|l|}{ フォントの色：自動 } \\
\hline ページ - 3 -: [3] 書式変更 & T. Saito & $2009 / 11 / 05 \quad 11: 54: 00$ \\
\hline \multicolumn{3}{|l|}{ フォントの色：自動 } \\
\hline ページ - 3 -: [3] 書式変更 & T. Saito & $2009 / 11 / 05 \quad 11: 54: 00$ \\
\hline
\end{tabular}




\begin{tabular}{|c|c|c|}
\hline ページ - 3 -: [3] 書式変更 & T. Saito & 2009/11/05 11:54:00 \\
\hline \multicolumn{3}{|l|}{ フォントの色: 自動 } \\
\hline ページ - 3 -: [3] 書式変更 & T. Saito & 2009/11/05 11:54:00 \\
\hline \multicolumn{3}{|l|}{ フォントの色: 自動 } \\
\hline ページ - 3 -: [3] 書式変更 & T. Saito & 2009/11/05 11:54:00 \\
\hline \multicolumn{3}{|l|}{ フォントの色: 自動 } \\
\hline ページ - 3 -: [3] 書式変更 & T. Saito & 2009/11/05 11:54:00 \\
\hline \multicolumn{3}{|l|}{ フォントの色：自動 } \\
\hline ページ - 3 -: [3] 書式変更 & T. Saito & $2009 / 11 / 05 \quad 11: 54: 00$ \\
\hline \multicolumn{3}{|l|}{ フォントの色：自動 } \\
\hline ページ - 3 -: [3] 書式変更 & T. Saito & $2009 / 11 / 05 \quad 11: 54: 00$ \\
\hline \multicolumn{3}{|l|}{ フォントの色：自動 } \\
\hline ページ - 3 -: [3] 書式変更 & T. Saito & $2009 / 11 / 05$ 11:54:00 \\
\hline \multicolumn{3}{|l|}{ フォントの色: 自動 } \\
\hline ページ - 3 -: [3] 書式変更 & T. Saito & $2009 / 11 / 05 \quad 11: 54: 00$ \\
\hline \multicolumn{3}{|l|}{ フォントの色：自動 } \\
\hline ページ - 3 -: [3] 書式変更 & T. Saito & 2009/11/05 11:54:00 \\
\hline \multicolumn{3}{|l|}{ フォントの色：自動 } \\
\hline ページ - 3 -: [3] 書式変更 & T. Saito & 2009/11/05 11:54:00 \\
\hline \multicolumn{3}{|l|}{ フォントの色：自動 } \\
\hline ページ - 3 -: [3] 書式変更 & T. Saito & 2009/11/05 11:54:00 \\
\hline
\end{tabular}




\begin{tabular}{|c|c|c|}
\hline ページ - 3 -: [3] 書式変更 & T. Saito & 2009/11/05 11:54:00 \\
\hline \multicolumn{3}{|l|}{ フォントの色: 自動 } \\
\hline ページ - 3 -: [3] 書式変更 & T. Saito & 2009/11/05 11:54:00 \\
\hline \multicolumn{3}{|l|}{ フォントの色: 自動 } \\
\hline ページ - 3 -: [3] 書式変更 & T. Saito & 2009/11/05 11:54:00 \\
\hline \multicolumn{3}{|l|}{ フォントの色: 自動 } \\
\hline ページ - 3 -: [3] 書式変更 & T. Saito & 2009/11/05 11:54:00 \\
\hline \multicolumn{3}{|l|}{ フォントの色：自動 } \\
\hline ページ - 3 -: [3] 書式変更 & T. Saito & $2009 / 11 / 05 \quad 11: 54: 00$ \\
\hline \multicolumn{3}{|l|}{ フォントの色：自動 } \\
\hline ページ - 3 -: [3] 書式変更 & T. Saito & $2009 / 11 / 05 \quad 11: 54: 00$ \\
\hline \multicolumn{3}{|l|}{ フォントの色：自動 } \\
\hline ページ - 3 -: [3] 書式変更 & T. Saito & $2009 / 11 / 05 \quad 11: 54: 00$ \\
\hline \multicolumn{3}{|l|}{ フォントの色: 自動 } \\
\hline ページ - 3 -: [3] 書式変更 & T. Saito & $2009 / 11 / 05 \quad 11: 54: 00$ \\
\hline \multicolumn{3}{|l|}{ フォントの色: 自動 } \\
\hline ページ - 3 -: [3] 書式変更 & T. Saito & 2009/11/05 11:54:00 \\
\hline \multicolumn{3}{|l|}{ フォントの色：自動 } \\
\hline ページ - 3 -: [3] 書式変更 & T. Saito & $2009 / 11 / 05$ 11:54:00 \\
\hline
\end{tabular}

